\title{
Emilia Pardo Bazán ante el drama musical de Richard Wagner. Descubrimiento, admiración y pasión (1873-1921)
}

\author{
Xosé-Carlos Ríos \\ (IES MANUEL MURGUÍA, ARTEIXO, A CORUÑA) \\ awgaliza@gmail.com
}

(recibido julio/2013, revisado septiembre/2013)

RESUMEN: El descubrimiento, admiración y pasión estética, literaria, escenográfica y musical que suscita la obra wagneriana en Emilia Pardo Bazán, no es tema secundario en la perspectiva y cosmovisión artística de nuestra autora. Desde una primera impresión normalizada en el mundo de la música, se va perfilando y construyendo en su particular jardín intelectual, una melomanía creciente, desarrollada con el paso del tiempo, que le Ileva inexorablemente a la revelación y agradable sorpresa del mundo de Richard Wagner y su amplio universo. En ella, es notoria la afición por la música y ópera en general, pero deviene en imprescindible converger el cosmopolitismo elitista de la misma, con la europeidad germanizada de un mundo por descubrir en la Mitteleuropa del momento, cada vez más abocada un enfrentamiento inevitable.

Pardo Bazán ve reflejada su idea de sensibilidad, ambientación, mensaje, poesía y transcendencia en la regeneración salvadora que toda obra de arte debe poseer, entiende de manera rápida y magistral, la forma y la misiva del Arte del Porvenir, tan falsamente controvertido; todo pues, lo abarca la obra wagneriana, conocidas y comentadas una a una por la ilustre pluma de la novelista y cronista, aunque le son de especial importancia, Lohengrin, La Walkyria y Parsifal, pues a medida que vamos profundizando en sus comentarios, parece que nos vamos dando cuenta mejor de lo que el mensaje literario e ideológico pardobazaniano nos quiere realmente transmitir.

PALABRAS CLAVE: Emilia Pardo Bazán, Richard Wagner, drama musical, ópera, Arte del Porvenir.

ABSTRACT: The discovery, admiration and the aesthetic, literary, scenographic and musical passions, that this wagnerian work creates in Emilia Pardo Bazán are not to be considered as a secondary themes in the perspective and the artistic worldview of our author. From the first normalized impression normalized in the music world, it one begins to outline and construct a growing in this particular intellectual garden, , developed with the passage of time, wich inexorably leads to the revelation and pleasant surprise of Richard Wagner's world and their broad universe. There, the passion for music and opera in general, is obvious, but it becomes indispensable to converge the cosmopolitan elitist itself with the germanized europeanness of a world one world find in the Mitteleuropa of the time, each time the inevitable confrontation becoming showdown.

Pardo Bazán sees this ideas of feeling, setting, message, poetry and the importance in the reparatory regeneration wich the all forms of art should possess, he quickly and flawlessly 
understands the form and the message of the Art of the Future, so falsely controversial; the wagnerian work encompasses emerything, well-known and commented-on, each for the illustrions pen of the novelist and columnist, although they are of special importance for her, Lohengrin, The Walkyria and Parsifal, because as we go deepening in its comments, it seems that we leave giving it counts better of what the message pardobazanian literary and ideological really wants to transmit us.

KEY WORDS: Emilia Pardo Bazán, Richard Wagner, musical drama, opera, Art of the Future.

"Es posible que, según la teoría de Wagner, mi oído necesite, para penetrarse de la belleza de la música, el auxilio de mi vista". E. Pardo Bazán, La vida contemporánea, La Ilustración Artística -LIA- (1906).

"Para comprender la obra de Wagner son indispensables dos premisas: reconocer que Wagner fue, ante todo y sobre todo, un poeta dramático; y observar al mismo tiempo que su instinto de poeta dramático era de una naturaleza especial, pues la palabra y el sonido musical le eran necesarios y alcanzaban igual importancia para la expresión de su concepción poética". H. S. Chamberlain, El Drama Wagneriano (1892).

"Además de compositor es poeta Wagner. Casi es más grande como poeta, y si sus libretos los escribe otro, no tendrían esa profunda compenetración con la música. Pueden definirse así las óperas de Wagner: un todo, indivisible, de música y poesía. A la larga, el poema decide la suerte de la música". E. Pardo Bazán, La vida contemporánea, LIA (1914).

\section{WAGNER Y SUS OBRAS EN LA CRÍTICA MUSICAL Y TEXTO LITERARIO DE E. PARDO BAZÁN.}

En pleno encantamiento por el mundo de la música y la ópera... aparece Richard Wagner en el amplio horizonte intelectual de nuestra ya nada novel escritora y desde su primer contacto y experiencia que ella misma narra cuando contempla y escucha, sorprendida, en Viena (1873) El Barco Fantasma/Holandés Errante, sobre el cual trataremos en este desarrollo pormenorizado de la obra wagneriana.

Es sintomática la indagación de la autora coruñesa por el compositor de Leipzig, pues va más allá del material escuchado y representado, siendo este, objeto de profundización intelectual; así lo afirmado, ya debía saber la coruñesa que su paradigma y persona de Émile Zola, era miembro de la Asociación Wagneriana de Marsella, y que ciertos recursos literarios remitían a los leitmotiv musicales del compositor alemán. No puede ser una casualidad ${ }^{1}$.

\footnotetext{
1 Magee, Bryan (2013), Aspectos de Wagner, ed. Acantilado, en p. 61 podemos leer en la cita de Zola, para sorpresa de algunos: "lo que llama usted repeticiones aparecen en todos mis libros. Es un recurso literario que empecé utilizando con cierta timidez, pero del que tal vez he llegado a abusar. Desde mi punto de vista, da más cuerpo a una obra y fortalece su unidad. El recurso es en cierta medida afín a los motivos de Wagner, y si pide usted a algunos de sus amigos músicos que le expliquen el uso que hizo de ellos, entenderá muy bien cómo utilizó el recurso en la literatura". ¿Y rastrear este mismo recurso de los temas conductores -leitmotiv- en la obra pardobazaniana?: podría ser...
} 
También lee y analiza la obra de Catulo Mendes, contemporáneo y amigo del maestro en París, donde estaba en la élite del arte parisino, entre otros con Renoir (el cuadro homenajeado de éste a sus hijas es muy conocido), titulada Ricardo Wagner, donde se informa de los problemas del músico para representar El Buque Fantasma (sic) en la Grande Opera de París (LIA, 6/III/1899). No nos consta ninguna obra de Mendes en la histórica Biblioteca de la Asociación Wagneriana de Madrid (AWM, 1911-1915). Sobre Catulo Mendes se narra la historia de su novelesco fallecimiento en otro artículo de La Ilustración Artística (LIA), como creador literario e intelectual, Catulo era, "imitador y discípulo del gran Teo [Teófilo Gautier]" (LIA, 1/III/1909) y desde esa perspectiva es calificado:

Poseía hasta un grado increíble el don de asimilación, no para recoger en su santuario lo que luego cociese en su hornillo, sino como mera habilidad en reproducir estilos y formas: (...) sinceramente fanático de Víctor Hugo y de Ricardo Wagner (...). Su campaña en pro de Wagner fue ilustrada y útil, y la realizó cuando en Francia se exteriorizaba la hostilidad hacia el semidiós (sic), con manifestaciones de un chauvinisme de mal gusto. (...) no puedo menos de aplaudir su campaña wagneriana, en la cual vino a darle la razón el tiempo.

Igualmente se remite la obra del músico y asiduo componente de los circunloquios wagnerianos de la casa Lhardy, "el Bayreuth madrileño"2, Rodrigo Soriano, cuya obra La Walkyria en Bayreuth (1898), sí nos figura como título y autor en la mencionada biblioteca de la AWM

amenísimo estudio (...) podía haber servido de catecismo a los profanos (...) La obra de Soriano me sirvió para entenderla [La Walkyria] y disfrutarla mejor en Madrid, donde, a pesar de bastantes defectos y faltas en el desempeño, atrezzo, mecánica, vestuario, colorido de la orquesta, etcétera, etc... (LIA, 6/II/1899).

2 Cfr. p. 47 de la magnífica obra de Ortiz de Urbina y Sobrino, Paloma (2007), Richard Wagner en España: la Asociación Wagneriana de Madrid (1911-1915), ed. UAH. El título completo de la obra de R. Soriano es La Walkyria en Bayreuth. Viaje a la Meca del Wagnerismo (1898), ed. Herres, Madrid. 
Puede llamar algo la atención el relativo (veremos que no es total) alejamiento por parte de la escritora ubicada en Madrid, en estos finales del XIX e inicios del $\mathrm{XX}$, de obras extraídas de los ambientes wagnerianos de Barcelona, como el Richard Wagner (1878) ${ }^{3}$ de Joaquín Marsillach (obras del mismo sí constaban en la biblioteca madrileña de la AWM, La Historia del Lohengrin -1882-...), inspirador directo de la que luego será la primera asociación wagneriana en España, la de la capital condal, y aquellas obras no fueran, decía, una referencia clara y profunda para quien quisiera adentrarse en las profundidades del bosque wagneriano. Igualmente y en esa línea, acontece con la difusión de la obra de Joaquim Pena (especialmente desde 1901) sobre prácticamente toda la obra del compositor con sus libretos íntegros y comentarios de gran calidad. Debió ser notable y de gran resonancia internacional el estreno del Parsifal en el Liceo, casi a la misma hora que expiaba el plazo para poder representar el Drama sacro en España: hablamos del 31 de diciembre de 1913. Madrid hará lo propio pocas horas después.

Lo que es definitivo, es que la Condesa conoce a la AWM, por lo menos así lo constata 1914, dándola ya casi por concluida, algo tal vez sintomático ${ }^{4}$ : "existía en Madrid una asociación wagneriana; se habían oído con interés respetuoso" (LN, 10/ II/1914).

Sobre el Parsifal y lo catalán, también se informa nuestra docta cronista, cuando nombra en su artículo de La Nación (LN, 17/I/1910, "Monsalvato, Lohengrin español"), la obra sobre el caballero del Grial, a un autor como Miguel Domenech (M. Domenech Espanyol), conocido en los ambientes barceloneses y liceístas, por sus obras, como ésta del mismo L'Apothéose musicale de la religion catholique. Parsifal, de Wagner, révélations démonstratives de la signification et symbolisme musical de cette oeuvre (1910), obra que influirá en algunos ángulos de opinión de nuestra autora sobre el Parsifal (LIA, 19/I/1914), autor también éste de otras obras como el

\footnotetext{
3 Marsillach, J., Richard Wagner, Barcelona, 1878. En posteriores años, son referencia los wagnerianos catalanes Soler i Rovirosa (escenógrafo), el tenor Francesc Viñas, Albert Bernis como empresario del Liceo, resaltando esa Die Walküre que Pardo Bazán resalta con tanto ánimo en su crónica barcelonesa de 1899 (v. LIA, 6/II/1899): “un aplauso a los señores Paris y Vehils, que como empresarios del Real y de nuestro Liceo respectivamente, han dado a conocer tan maravillosa partitura [cfr. La Walkyria y el Anillo del Nibelungo íntegro en general]. Detrás de Vehils, estaba casi sin duda, el empresario catalán y gran wagneriano Albert Bernis, que difunde y hace estrenar casi todas la producciones liceístas entre 1882 y 1910: Lohengrin (1884), Tannhäuser (1887), El Oro del Rhin (1910). Maestros Cantores (1905), La Walkyria (1899), Tristán e Isolda (1899), Sigfrido (1900) y El Ocaso de los dioses (1901).

En el llamado “círculo de Bayreuth" de Villa Wahnfried, destacaban varios españoles, además de los mencionados catalanes (Marsillach y J. Pena), el gran pintor santanderino Rogelio de Egusquiza y el escritor Dr. Letamendi.

4 La Asociación Wagneriana de Madrid se funda en 1911, pero desaparece de una manera un tanto abrupta en 1915, casi coincidiendo con el estallido de la primera Guerra Mundial (1914-1918) y el ambiente de la capital entre pro-aliados y pro-alemanes, estos últimos en evidente minoría.
} 
Tristán e Isolda (1906), dador también de conferencias sobre temas wagnerianos en el Ateneu barcelonès 5 .

Menos aún pudieron pasar por alto autores ya ligados a la entidad wagneriana de Madrid, formalizada desde 1911, como ya hemos relatado. Destacan en ella eminentes socios wagnerianos e intelectuales como el mismo Siegfried Wagner (hijo de Richard y socio de honor, 1869-1930), el gran pintor santanderino Rogelio de Egusquiza (1845-1915) y el compositor Luis Mancinelli (1848-1921, verdadero impulsor de Wagner en Madrid, director de las primeras sesiones del Tannhäuser en 1890, entre otras ${ }^{6}$ ), músicos cuales Enrique Fernández Arbós y Conrado del Campo, el germanófilo historiador Adolfo Bonilla y San Martín, aliadófilos como Álvaro AlcaláGaliano (periodista), Gregorio Marañón, el creativo escenógrafo Amalio Fernández, las cantantes Concepción Dahlander y Lucrecia Arana; de la Sociedad Filarmónica madrileña, Félix Arteta, o la viuda de Ruperto Chapí, con la cual sabemos, nuestra escritora estuvo en el funeral que ella misma relata en La Nación (1909). La huella wagneriana ya se plasma en la musicología gallega: María del Adalid era socia desde el año fundacional de 1911, y Jesús Bal y Gay, compositor y musicólogo, difundirá desde la revista Ronsel (Lugo y Madrid, donde ya reside desde 1921) la obra del autor alemán ${ }^{7}$.

No podemos dejar de señalar las tertulias madrileñas en los ambientes wagnerianos de los tiempos modernistas, eran sus centros el Café Español, Café Suizo, el bohemio Café de los Nigrománticos, Café Levante, o la Casa Lhardy o "el Bayreuth madrileño" (carretera de San Jerónimo no 8) ya mencionado. En dicha Casa eran asiduos tertulianos Julián y Miguel Gayarre, músicos como Félix Arteta, Pablo Sarasate, Manrique de Lara y el comentado Rodrigo Soriano. No puede extrañarnos ver en estos círculos a Benito Pérez Galdós (su contribución con temática wagneriana resaltaba en diarios como La Nación -1865- y sus sentimientos con la escritora son más que constatables desde finales de la década de los 80 , sin olvidar el viaje que realizaron juntos a Alemania ${ }^{8}$...), taimado admirador del compositor alemán (al igual

\footnotetext{
5 Artículo de Sagalés, Josep $\mathrm{M}^{\mathrm{a}}$, “Memorias de un wagneriano", Rev. Wagneriana castellana, $\mathrm{n}^{\circ} 40$, 2001, p. 2.

${ }^{6}$ El estreno del Tannhäuser en El Real corre a su cargo, junto con Los Maestros Cantores de Nuremberg, en 1893.

7 Revista Ronsel, no 1, "Richard Wagner", Lugo, 1924, p. 9. "Ricardo Wagner": este breve pero muy sentido texto de Jesús Bal, reproduce también en fotografía la "cabeza de Wagner” del escultor madrileño Julio Antonio.

8 Sus trabajos de Por Francia y Alemania para El Imparcial los hace junto con Benito Pérez Galdós, a finales del verano de 1889, sin duda este viaje fue definitivo para conocer y admirar Alemania, al mismo tiempo que charlar de Wagner: seguro. En las recién editadas cartas personales Pardo BazánGaldós, se refiere la primera a dicha travesía en las respectivas de septiembre y octubre de 1889 (pp. $82,144-145,148)$, con un final "Habla de Alemania lo menos que puedas, a tu vuelta" (Miquiño mío, 2013, v. bibliografía).
} 
que su probablemente sobrino Ignacio Pérez Galdós, socio de la AWM) como nos referencia el músico Rogelio Villar cuando detalla la admiración de aquél por la estética que emanaba Wagner, nombrando un cuadro de nuestro compositor en su casa, al igual que el director del Real, Luis París, todos conocidos (algunos, íntimos) por la novelista coruñesa. Nada de todo lo comentado pudo pasar desapercibido para la atenta mirada y aguda percepción de La vida contemporánea.

Wagner, andando la década de los ochenta es ya la referencia obligada de buen gusto y profundidad de sentimientos a través de la música, en la hora misma de la metanoia más espiritual: "más dramático y musical que ningún coro de Wagner..." (VPE/MR -Mi Romería-, 1888, p. 76), apreciaciones que hacen criticar muy severamente al público madrileño del momento:

El bostezo del público del Real ha sido meramente una protesta contra la atención y el recogimiento que exige la música de Wagner. Nada que obligue a concentrarse, nada que mueva a reflexión (...) Hay mucho de leyenda en eso de que sea preciso estudiar metafísica o matemáticas sublimes antes de comprender a Wagner. La suma belleza artística siempre es directa, fulminante, fuerte y poderosa. Se impone. ¡Y sostener que Wagner adormece! Lo que hace es despabilar. Una audición sentida de La Walkyria consume mucho fluido nervioso. (LIA, 6/II/1899).

No deja en absoluto indiferente la apreciación general sobre el compositor alemán a nuestra autora, ahora convertida cronista y crítica musical, aun sin pretenderlo, la pasión le lleva... hasta proponerlo como ejemplo de restaurador y regenerador de los pueblos, merced a su arte, su belleza:

No cabe duda, Ricardo Wagner es el último genio que ha producido Alemania (...) a los genios alemanes les caracterizan dos atributos: la extensión y la profundidad (...) en el cual [idioma] las palabras se sujetan, amoldan o ciñen a la idea con plasticidad sorprendente, ayudadas de una sintaxis que dimana de la razón, más que de las exigencias retóricas y descriptivas (...). Y ya creo que puede afirmarse que ningún artista poseerá en mayor grado que Wagner el tecnicismo y la inspiración reunidos, y el sentido a la vez poético y profético que hace del artista la encarnación de los destinos de un pueblo, de una raza, de un conjunto humano (...).Traer a Madrid la obra titánica de Wagner, no se figurarán muchos que tiene que ver gran cosa con esa regeneración de que tanto nos hablan; pues desengáñense; la belleza es un regenerador poderoso. Algunos profesamos como dogma que todo lo bello es necesariamente bueno. Y los pueblos en que se ha cultivado la sacrosanta belleza, no han sido por cierto ni los menos heroicos ni los de menos gloriosos destinos (...). El arte es más necesario que el pan; el pan solo, seco, desabrido, ni gusta ni aprovecha. Venga esa gran corriente de poesía del Norte a inundar nuestras almas agostadas por la desconfianza y el dolor. (LIA, 6/III/1899).

De lo más importante a nuestro entender, es el vínculo que Emilia Pardo Bazán, que al ver-contemplar y escuchar los dramas wagnerianos, establece con la forma y el significado de su mensaje artístico, ético y estético. No era fácil de percibir 
en su tiempo lo que Richard Wagner quería demostrar con sus obras. La música y tradición operística en general ítalo-francesa segmentaba, disponía, separaba el lenguaje musical de la directa insinuación del mensaje del texto-libreto poético que los cantantes simplemente reproducían. No solo eso, la música en sí misma, era reinterpretada por Wagner como una expresión unitaria entre la melodía, el texto (la palabra, la importancia del sonido de las consonantes) como entramado musical (armonía, melodía y su tonalidad), los cantantes y la orquesta ("fuerza que domina las aguas de la armonía"9 $)$, todo ello en una sinfonía-armonía que entendía, finalmente la pieza a representar como un uno dramático (escénico, trágico-griego) y por lo tanto, también visual y plástico (escenografía, atrezzo, tramoya, puesta de escena). Finalmente es también la atracción por el mito y la "religión más elevada de lo humano", que acabará en el cristianismo parsifaliano... Es el "Arte del Porvenir", el "Drama del Futuro", el Drama wagneriano:

La melodía redime a la idea poética eternamente, condicionada, elevándola a la conciencia, muy sentida, de la más alta libertad emocional. Ella es lo espontáneo buscado y manifestado a propósito, lo inconsciente consciente y claramente propagado, la necesidad justificada basada en un fondo que desde la ramificación más amplia se concentró en la más determinada exteriorización del sentimiento y cuya amplitud es ilimitada (La Poesía y la Música en el Drama del futuro-1849-, R. Wagner, pp. 51-52).

Cuando la marinedense exponga con claridad cristalina los elementos básicos de una obra de "Arte total", procedente sin duda de sus ideales estéticos y literarios que promulgan un regeneración de la intelectualidad, y por ende de la necesidad de elevar el nivel cultural de todo un pueblo español y europeo, las piezas ya están siendo encajadas en el discurso más regeneracionista posible. Para empezar, la precisión de rehacer convenientemente forma y mensaje de las óperas:

Los libretos de ópera necesitan ser dramáticos, antes que psicológicos. Hondas psicologías y extrañas formas de pensamiento religioso y humanitario, nunca darán un libreto de ópera que interese y que inspire. Y no son excepción de esta regla los magníficos libretos de Wagner. Llenos de simbolismo y de sentido tradicional, hay en ellos siempre mucho drama, mucho amor, mucha vida, mucha muerte, y ese elemento fantástico y sobrenatural, que tanto se presta a los esplendores del escenario. (LIA, $\mathrm{n}^{\circ} 1.568$, p. 46, 15/01/1912).

¡Y el libreto ha de estar a la altura de la música!:

9 in Wagner, Ricardo (1952), La poesía y la música en el Drama del futuro, ed. Austral, Madrid. La cita es de p. 77. 
En Parsifal hay que considerar dos cosas: el poema y la partitura. Como siempre sucede en la obra de Wagner, el libreto está a la altura de la música. Para escribir estos libretos admirables, Wagner no ha empleado más que un procedimiento: no inventar; limitarse a aprovechar la tradición y la leyenda, desentrañando, con la poesía y la música, su oculto simbolismo. Para Wagner, como para Baudelaire, el mundo es una selva de símbolos, y voces misteriosas los murmuran, saliendo de los árboles centenarios de esa selva (LIA, 19/I/1914).

Definitivamente, la comprensión de la autora hacia el Arte del Porvenir es casi perfecta, "un todo indivisible de música y poesía":

Además de compositor es poeta Wagner. Casi es más grande como poeta, y si sus libretos los escribe otro, no tendrían esa profunda compenetración con la música. Pueden definirse así las óperas de Wagner: un todo, indivisible, de música y poesía.

A la larga, el poema decide la suerte de la música (...).

Pero no conozco asuntos ni libretos comparables a los de Wagner. Publicados sin música, como poemas, hubiesen logrado, para su autor, un lugar eminentísimo entre los vates alemanes. Hay dos cosas dignas de notarse en los poemas de Wagner: una, el carácter tradicional; otra, el modernísimo sentimiento. Uniendo el pasado al presente con lazos de oro, Wagner ha logrado quitar a la evocación del ayer esa frialdad arqueológica, ese gris de telaraña, que la apartan de nosotros, y la aíslan de la vida actual. No hay gente más moderna y contemporánea, en cierto respecto, que Tristán, Iseo, el caballero Tannhäuser y el héroe Sigfrido (...).

Los problemas de nuestra conciencia están simbolizados en la infernal tradición del Venusberg, con la diablesa que pierde a los hombres, en el certamen de la Wortburga, en la figura célica de Santa Isabel, y surge de esta evocación el poema del pecado y del arrepentimiento, el milagro y el perdón. Lohengrin, cuya idea es el misterio, representa la caballería, fruto de las cruzadas y del catolicismo. Elsa es una figura angélica, digna de un vitral. (LIA, 21/XII/1914).

La escenografía, lo veremos, es esencial (después de lo musical y textual) para comprender el universo wagneriano, "el mundo de la luz" en palabras del maestro ${ }^{10}$, un todo de artes plásticas donde los telones pintados, la tramoya (movimiento, traslación de elementos artificiales y subrayado de los mismos en la acción operístico-dramática), atrezzo, utilaje, esciografía de luces/sombras, materiales

\footnotetext{
10 En el precioso artículo de Massana, Juan (1978), “Escenario y símbolo en la obra de Wagner”, rev. Wagneriana, vol II, pp. 11-16, se cita un texto del entendido Alfred Ernst: "En el drama, síntesis de la vida, hay un mundo óptico, un conjunto de sensaciones visuales indispensable a la sensación y belleza de la obra (este conjunto de sensaciones es denominado por Wagner "el mundo de la luz", Lichtwelt). Los tienen también su dominio, como las orejas, como el intelecto, y pide un orden especial de hecho y de relaciones. La forma, el color, las combinaciones de unos y de otros, y, sobre todo, su movimiento, son factores importantes del efecto escénico. Es preciso asegurar la armonía de estos elementos en sus manifestaciones vivientes, individuales -los personajes- y también en el medio donde se desarrolla la acción -el decorado-”. pp. 13-14.
} 
ópticos, son un todo con el texto (libreto poético, rimado), música (voz y orquesta) y acción dramática del cantante.

La tradición escenográfica del momento donde nos situamos, es en una primera fase del desarrollo un "arte menor" en el cual se va transitando desde las indicaciones del propio compositor (en esto Wagner era especialmente meticuloso...), a la edición de las diferentes representaciones en los teatros de Europa con mayores o menores recursos económicos. Una primera etapa por lo tanto iría desde el final del siglo XIX a la $1^{a}$ Guerra Mundial, una segunda época desde el período de entreguerras y el último conflicto bélico acabado en 1945, y una última, en la que todavía estamos, de posguerra, donde ya se "experimenta" totalmente al margen de las intenciones del autor y su obra: podemos decir, que salvo honrosas excepciones, pura especulación de decoradores y directores de escena del mundo del teatro "progre", reciclados a "escenógrafos" del tan distinto y singular mundo de la ópera: el resultado actual ya lo estamos viendo a día de hoy...en el supuesto que la Condesa viviera, no duden cuál sería su posicionamiento al respecto.

Sobre artes plásticas (pues el drama en sí mismo es también "plástico", a diferencia de lo musical) y escenografía operística, son múltiples las notas de la articulista de La vida contemporánea, seleccionamos estas:

Estos últimos tiempos del Real han sido de abatimiento (...) fueron fatales en lo tocante al aparato, vestuario, decoraciones y mise en scène. Jamás he comprendido por qué el Real había de tener el privilegio y el fuero de exhibir, sin que nadie protestase, las impropiedades más chocantes, los disparates más estupendos y las mayores ridiculeces. En el Orfeo, de Glück, he visto a Orfeo buscando a Eurídice por una selva de cocoteros, palmera y lianas tropicales. En Lucia de Lammermoor la tiple saca botas de raso y vestido de cola, para esperar a Edgardo en el parque. La banda de música que entona en el escenario la marcha de Aida, sopla del triunfo de Radamés en instrumentos de fines del siglo XIX. Norma se pasea con zapatitos Luis $\mathrm{XV}$, al pie del roble del Irminsul. Los coristas no se afeitan; parecen bandidos cuando hacen de caballeros, y parecen unos honrados cesantes cuando hacen de bandidos; lucen medias de algodón y botas de elástico en la conjura de Hernani, por debajo de las amplias capas, y en Gioconda, donde les cumplían trajes venecianos, se presentan con una especie de birretes amelonados y unas trusas, a lo Tenorio en provincia.

Diríase que son inconciliables la propiedad y verosimilitud y el drama lírico. Jamás comprenderé por qué en Traviata, verbigracia, las mujeres visten a la última moda, y los hombres con casacón y peluca; ni por qué en el Barbero de Sevilla D. Bartolo lleva el atavío de los personajes de Molière. Estas inexactitudes son fáciles de evitar, y contra ellas se ha clamado mil veces sin conseguir modificar la rutina (...). La admirable orquesta compensaba las deficiencias de atrezzo y guardarropa, y hasta cubría los deslices de los cantantes en lid mortal con afonías y catarros. (LIA, 20/I/1896).

Apenas estrenada La Walkyria ya se toman confianzas con ella. No hablemos del ridículo modo de vestir de la tiple, que sale de Sieglinda con corsé muy entallado y tacones Luis XV; pero el rayo de Wotan, que tronza la espada de Segismundo, 
ha sido suprimido por completo desde el primer día, y el descuido y negligencia son tales, que en la famosa cabalgada de la Walkyrias se ve cruzar las nubes a una guerrera con manto verde, y a los tres segundos, habiéndose mudado sin duda, aparece en escena con manto rojo. (LIA, 20/III/1899).

A cada temporada se recorta algo, no sólo de la música, que eso ya es pan comido, sino de lo puramente escénico (...) En Gioconda, el bergantín tiene que arder. Ardía hace unos dos o tres años: ya no arde; sin duda es más cómodo. En Orfeo, el banco donde se recuesta Eurídice lo sacan de la escena tirando de un cordel, sin disimulo. ¿Qué más da? La cueva de Venus, en Tannhäuser, se la llevan, a vista de todos, unos tramoyistas, cuyas viejas botas asoman por debajo de los peñascos, reclinatorio de la diosa. El cisne y la paloma de Lohengrin son impagables, de puro infantiles (...) En las riberas del Peneo de Mefistófeles, debe haber grupos de sirenas; Elena debe Ilegar en una barca; pero Ilega andandito, que es más higiénico (...) Se ha erigido en costumbre restar de ciertas óperas actos o cuadros enteros: así, el último de Hugonotes y el de la sfida de Lucía. Malo es esto, pero encuentro más intolerable lo otro, porque, al menos, lo que se presente al público, entero o desmembrado, debe presentársele en condiciones que no lo desmejoren y lo hagan ininteligible (LIA, 27/II/1905).

¿Es que no se producen ya óperas notables? (...) Porque si así no fuese, habría que mostrarse doblemente severos con la empresa (...). El año pasado se nos presentó una operita, Ilamada nueva, pero muy antigua (...) era una especie de Linda de Chamounix echada a perder, y en ella había una decoración con pinos verdaderos que oscilaban bajo el vendaval furioso, alarde de realismo que nos costó varios sustos, porque, mal asegurados, a poco matan a la tiple cayéndose sobre la cabeza. Era aquello una pesadilla, y en vez de oír a los cantantes, no hacíamos sino temblar (LIA, 15/I/1912).

Definitivamente, la escenografía, al igual que el libreto literario, es esencial, junto con la música, para captar el mensaje wagneriano en toda su extensión e intensidad:

[la decoración] Es posible que, según la teoría de Wagner, mi oído necesite, para penetrarse de la belleza de la música, el auxilio de mi vista (...) En el templo todo os sugiere el misterioso estado de ánimo a que la música responde fielmente. Las altas columnas, el murmullo tenue de la muchedumbre que se agolpa en la nave, la semiobscuridad, el olor casi disipado del incienso, el parpadeo de los cirios en el altar de oro, sombrío, de antiguas coloraciones..., constituyen una decoración del gusto de Wagner (el artista que mejor ha comprendido la estrecha, la íntima relación de la mise en scene teatral y la mise en scene religiosa) (LIA, 8/X/1906).

Finalmente, los elogios y referencias hacia Wagner persona y en general, dentro de su creación puramente literaria, son del estilo, como en su ya modernista y espiritualista novela La Quimera, "una corriente gemela de la prerrafaelista ha producido la inspiración del inefable Wagner" ; "El amor me ahogaba. Wagner me había despertado" (LQ -La Quimera, 1905- pp. 482-483 y 490). 
En este sentido, la figura de Wagner continúa apareciendo en la narrativa de la autora en otras obras, amén de la mencionada, en Clave (1909), en el mismísimo comienzo del corto relato: "El famoso compositor y profesor de canto y música Alejandro Redlitz se entretenía en leer sin instrumento una de las últimas páginas de su amigo Ricardo Wagner". Hasta ya se hacía familiar a sus personajes.

Para una mejor comprensión de la incidencia de determinados números de ítems en las obras de este especial drama musical, caben ahora los siguientes esquemascuadros, 1 y 2 :

Cuadro 1. REFERENCIAS A LOS TEMAS Y DRAMAS WAGNERIANOS EN LA OBRA DE E. PARDO BAZÁN. NARRATIVA CORTA, NOVELAS Y CRÓNICAS EUROPEAS.

\begin{tabular}{|c|c|c|c|c|c|c|c|c|c|c|c|}
\hline & $\begin{array}{c}\text { VPE/MR } \\
1888\end{array}$ & $\begin{array}{c}\text { VPE/FyA } \\
\text {-APTE } \\
1889\end{array}$ & $\begin{array}{c}\text { Por el } \\
\text { arte } \\
1891\end{array}$ & $\begin{array}{l}\text { VPE/ } \\
\text { Exp. } \\
1900\end{array}$ & $\begin{array}{c}\text { VPE/ } \\
\text { EC } \\
1902\end{array}$ & $\begin{array}{c}\text { La } \\
\text { Quimera } \\
1905\end{array}$ & $\begin{array}{c}\text { La } \\
\text { Sirena } \\
\text { Negra } \\
1908\end{array}$ & $\begin{array}{c}\text { El } \\
\text { disfraz } \\
1909\end{array}$ & $\begin{array}{l}\text { Clave } \\
1909\end{array}$ & $\begin{array}{c}\text { Dulce } \\
\text { Dueño } \\
1911\end{array}$ & $\begin{array}{c}\text { Durante el } \\
\text { entreacto } \\
1911\end{array}$ \\
\hline Lohengrin & & $x x$ & & & & & & $x$ & & $x$ & \\
\hline Tannhäuser & & $x$ & & & & & & & & & \\
\hline $\begin{array}{l}\text { Parsifal / } \\
\text { Grial }\end{array}$ & & & & & & & & & & $x$ & \\
\hline $\begin{array}{l}\text { Wagner/ } \\
\text { autor-obra }\end{array}$ & $x$ & $x x$ & & & & $x$ & & & $x$ & & \\
\hline $\begin{array}{l}\text { Mitologia/ } \\
\text { Leyendas } \\
\text { germánicas }\end{array}$ & & & & $x$ & $x$ & $x$ & & & & $\mathrm{x}$ & \\
\hline $\begin{array}{l}\text { Ondinas } \\
\text { del Rhin }\end{array}$ & & $x$ & & & & & $\mathrm{x}$ & & & $x$ & \\
\hline $\begin{array}{l}\text { Ocasos de } \\
\text { los Dioses }\end{array}$ & & & & & & & & & & & $x$ \\
\hline Bayreuth & & $x$ & & & & & & & & & \\
\hline
\end{tabular}

Notas:- VPE (Viajes por Europa): MR (Mi Romería)-FyA (Por Francia y Alemania)-APTE (Al pie de la Torre Eiffel)-Exp (Cuarenta días en la Exposición) y EC (Por la Europa católica). 
Cuadro 2. ARTICOLOGÍA DE E. PARDO BAZÁN REFERIDA A DRAMAS Y TEMAS WAGNERIANOS.

\begin{tabular}{|c|c|c|c|c|c|c|c|c|c|c|c|c|c|c|c|c|c|c|}
\hline & \begin{tabular}{|c|} 
LIA \\
1879
\end{tabular} & $\begin{array}{c}\text { LIA } \\
1899 \\
(1)\end{array}$ & \begin{tabular}{|c|} 
LIA \\
1899 \\
$(2)$
\end{tabular} & $\begin{array}{c}\text { LIA } \\
1899 \\
(3)\end{array}$ & \begin{tabular}{|c|} 
LIA \\
1899 \\
$(4)$
\end{tabular} & \begin{tabular}{c|} 
LIA \\
1900 \\
1902 \\
\end{tabular} & \begin{tabular}{|c} 
LIA \\
1905 \\
1906
\end{tabular} & \begin{tabular}{|c|} 
LIA \\
1907 \\
1098 \\
1909 \\
1912 \\
1913 \\
\end{tabular} & $\begin{array}{c}\text { LIA } \\
1914 \\
(1)\end{array}$ & $\begin{array}{c}\text { LIA } \\
1914 \\
(2)\end{array}$ & $\begin{array}{c}\text { LIA } \\
1915 \\
1916\end{array}$ & $\begin{array}{c}\mathrm{LN} \\
1909\end{array}$ & \begin{tabular}{|c|} 
LN \\
1910
\end{tabular} & \begin{tabular}{|c} 
LN \\
1912
\end{tabular} & \begin{tabular}{|c} 
LN \\
1913
\end{tabular} & $\begin{array}{r}\text { LN } \\
1914\end{array}$ & \begin{tabular}{|c|} 
LN \\
1916 \\
1918
\end{tabular} & \begin{tabular}{|c} 
LN \\
1919 \\
1920
\end{tabular} \\
\hline Lohengrin & & $x$ & & $x$ & & $x$ & $x$ & $x$ & $x$ & $x$ & & & $x$ & $x$ & $x$ & $x$ & & $x$ \\
\hline Rienzi & & & & & & & & & $\mathrm{x}$ & $\mathrm{x}$ & & & & $x$ & & $\mathrm{x}$ & & \\
\hline $\begin{array}{l}\text { Parsifal/ } \\
\text { Grial }\end{array}$ & & $\mathrm{x}$ & & & & & & & $\mathrm{x}$ & $\mathrm{x}$ & $x$ & & $x$ & $x$ & $\mathrm{x}$ & $x x$ & & $x x$ \\
\hline Tannhäuser & & $\mathrm{x}$ & & & & & $x$ & $\mathrm{x}$ & $x$ & $\mathrm{x}$ & & & $x$ & $x$ & & $\mathrm{x}$ & & \\
\hline \begin{tabular}{|l} 
Barco \\
Fantasma
\end{tabular} & & & $x$ & & & $x$ & & & $\mathrm{x}$ & $\mathrm{x}$ & $x$ & & & & & & & \\
\hline \begin{tabular}{|l} 
Tristán e \\
Iseo
\end{tabular} & & & & & & & & & $\mathrm{x}$ & & $x$ & & $x$ & $\mathrm{x}$ & & $\mathrm{x}$ & & \\
\hline $\begin{array}{l}\text { Anillo, El } \\
\text { (gral.) }\end{array}$ & & & & & & & & & $x$ & & & & & $x$ & & & & \\
\hline $\begin{array}{l}\text { Wagner } \\
\text { autor-obra }\end{array}$ & $x$ & & & & $\mathrm{x}$ & $x$ & $x x$ & $x x x x$ & $\mathrm{x}$ & $\mathrm{x}$ & $x x$ & $x x$ & $x$ & $x x$ & $\mathrm{x}$ & $x x$ & $x$ & $\mathrm{x}$ \\
\hline $\begin{array}{l}\text { Mitología/ } \\
\text { leyendas } \\
\text { germánicas }\end{array}$ & & & & & & & $\mathrm{x}$ & $x$ & $\mathrm{x}$ & $\mathrm{x}$ & $x$ & & $x$ & $\mathrm{x}$ & & & $\mathrm{x}$ & \\
\hline $\begin{array}{l}\text { Ondinas } \\
\text { del Rhin }\end{array}$ & & & & & & & $\mathrm{x}$ & & & & & & $x$ & $\mathrm{x}$ & $\mathrm{x}$ & & & \\
\hline $\begin{array}{l}\text { Walkyria, } \\
\text { La }\end{array}$ & & $\mathrm{x}$ & $x$ & $x$ & & $x$ & & & $x$ & & & $x x$ & & $\mathrm{x}$ & $\mathrm{x}$ & $x$ & & $x$ \\
\hline $\begin{array}{l}\text { Personajes } \\
\text { wagn } \\
\text { (gral.) } \\
\end{array}$ & & & $x$ & $\mathrm{x}$ & & $x$ & & & $\mathrm{x}$ & & & & $x$ & $\mathrm{x}$ & & $x x$ & $x$ & \\
\hline $\begin{array}{l}\text { Oro del } \\
\text { Rhin, El }\end{array}$ & & & & & & & & & $x$ & & & & & & & $x$ & & \\
\hline Siegfried & & & & & & & & & $\mathrm{x}$ & $\mathrm{x}$ & $x$ & $x$ & & $x$ & & $x$ & & $x$ \\
\hline $\begin{array}{l}\text { Ocaso } \\
\text { dioses }\end{array}$ & & & & & & & & & $x$ & & & & $x$ & & $\mathrm{x}$ & $\mathrm{x}$ & & \\
\hline Bayreuth & & & $x$ & & & & & & & & & & & $x$ & $\mathrm{x}$ & $\mathrm{x}$ & & \\
\hline $\begin{array}{l}\text { Maestros } \\
\text { Cantores }\end{array}$ & & & & & & & & & & & & & & & & $x$ & & \\
\hline \begin{tabular}{|l} 
Luis II \\
Baviera
\end{tabular} & & & & & & & & & & & & & $\mathrm{x}$ & $x x$ & & & & \\
\hline
\end{tabular}

Notas al cuadro 2.- LIA (La Ilustración Artística), LN (La Nación de Buenos Aires, con fecha de publicación).

1879: LIA 25/XII/1879

1899: LIA 6/II/1899 (1), LIA 6/III/1899 (2), 20/III/1899 (3) y 2/X/1899 (4)

1900-1902: LIA 29/I/1900, LIA 26/II/1900 y LIA 1/I/1902

1905-1906: LIA 17/II/1905, LIA 29/I/1906 y LIA 8/X/1906

1907-1908-1909-1912-1913: LIA 1/I/1907, LIA 3/II/1908, LIA 1/III/1909, LIA 20/XII/1909, LIA 15/I/1912 y LIA 3/III/1913

1914: LIA 9/I/1914 (1), LIA 21/XII/1914 (2), LN 12/IX/1914

1915-1916: LIA 19/VII/1915, LIA 13/III/1916, LIA 14/VI/1916 y LIA 11/XII/1916

1909: LN 28/IV/1909, LN 6/VI/1909 y 23/VI/1909

1910: LN 17/I/1910, 12/III/1910 у 1/IV/1910 
1912: LN 1/IV/1912 y LN 12/IV/1912

1913: LN 27/XII/1913

1914: LN 10/II/1914 y LN 5/X/1914

1916-1918: LN 21/VII/1916 y LN 17/VII/1918

1919-1920: LN 25/V/1919 y LN 20/I/1920

Ítems parciales (una vez nombrada la obra operística en el artículo-obra narrativa en concreto ésta equivale a un solo ítem, aunque sea reiteradamente nombrada a lo largo de dicho trabajo literario) y totales de dramas y temas wagnerianos referidos en articología (Cuadro 1) y narrativa-crónicas VE (Cuadro 2):

\section{Dramas musicales/Óperas:}

Lohengrin: 12 (Cuadro 2) / 4 (Cuadro 1): 16 ítems

Parsifal-Grial: 11 / 1: 12 ítems

La Walkyria: 11 / 0: 11 ítems

Tannhäuser: 8 / 1: 9 ítems

Siegfried: 7 / 0: 7 ítems

Ocaso de los dioses: 4 / 1: 5 ítems

Barco Fantasma: 5 / 0: 5 ítems

Tristán e Iseo: 4 / 0: 4 ítems

Rienzi: 4 / 0: 4 ítems

El Anillo (gral.): 2 / 0: 2 ítems

El Oro del Rhin: 2 / 0: 2 ítems

Maestros Cantores de Nuremberg: 1 / 0: 1 ítem

Temas wagnerianos:

Wagner autor-obra: 23 / 5: 28 ítems

Mitología/Leyendas germánicas: 8 / 4: 12 ítems

Personajes wagnerianos (gral.): 9 / 0: 9 ítems

Ondinas del Rhin: 4 / 3: 7 ítems

Bayreuth: 4 / 1: 5 ítems

Luis II de Baviera: 3 / 0: 3 ítems

TOTAL GENERAL ÍTEMS: 142

2. EL BUQUE FANTASMA / EL HOLANDÉS ERRANTE (1873 / 1896) Y RIENZI (1876).

El descubrimiento. Ya nos hemos referido en alguna ocasión al acontecimiento que pudo significar para la señora de Quiroga, el asistir a su personal experiencia en Viena, 1873 (ó ¿1872? pensamos que no), durante la visita y curioseo de la Exposición Universal de la capital del Imperio Austro-Húngaro, después de su casamiento con José Quiroga en 1868. Es una experiencia que la inicia en un europeísmo militante, ya inmediatamente antecedido de viajes a Gran Bretaña y Francia; allí, como 
sabemos, analiza la belleza de la emperatriz Elisabeth (Sissí) ${ }^{\mathbf{1 1}}$ de Austria-Hungría (amiga o novia de Luis II), también asistente a la representación, ya esposada aquélla, con el Emperador Francisco José:

Nadie más entusiasta del maestro que yo. Cuando en Viena, en el Teatro Imperial, asistí a una representación del Barco Fantasma (era el año 1872 ó 73, y yo bien joven, y bien ignorante en materia, tanto que el nombre de Wagner no había llegado jamás a mí), recuerdo que me entusiasmé, y declaré a los que me acompañaban que quien había escrito tal partitura era un genio (...) Yo seguí creyendo que era un genio, y de los más extraordinarios; y sin embargo, como se sabe, no es el Barco Fantasma la mejor ni la más típica de sus obras. Claro es que me postro y me abismo ante Wagner; con todo eso, la proporción sigue pareciéndome una de las leyes eternas de la estética universal. (LIA, 19/I/1914).

El Barco fantasma no es lo mejor de Wagner, pero lleva la huella del genio, y encierra trozos de sorprendente hermosura. El coro de los marineros condenados, que tripulan el buque errante con su siniestro cargamento de muertos, a través del Océano, me impresionó, así como el canto, tan misterioso, de las hilanderas. (LIA, 21/XII/1914).

También es comparado el personaje de Senta, trágico, con el de la emperatriz, después asesinada (1898):

[en esa misma velada] Se cantaba El barco fantasma, de Wagner, y yo jamás había oído música del maestro. La noche me dejó inolvidable impresión, no sólo porque (desmintiendo esa leyenda de que para entender a Wagner hay que ir a Salamanca, y no sé si a otras Universidades), yo entendí perfectamente y desde el primer momento que aquello era sublime, sino porque vi, en el largo espacio de los entreactos, a la pareja imperial (...). ¡Pobre soberana! También ella, como Senta, la heroína del libreto wagneriano, Ilevaba en el alma una leyenda, una balada nostálgica, Ilena de misterio y de romanticismo. También en ella (...), el Rey virgen

\footnotetext{
11 LIA, 21/XII/1914: Emilia Pardo Bazán acude a la representación del Barco Fantasma y, aprovechando, describe la belleza física ("cuello císneo": por cierto, adjetivo que le gustaba especialmente a la escritora, amén de su admiración personal por los cisnes) de Isabel de Austria-Hungría, también asistente (aunque les pese a unos cuantos, también wagneriana) a dicha velada. Dos son los años que nos informa la joven noticiera, pues la duda ya la asalta en 1914 ("Cuando en Viena, en el Teatro Imperial, asistí a una representación del Barco Fantasma (era el año 1872 ó 73, y yo bien joven...”), en este mismo LIA: La primera posibilidad es 1872: la fecha de dicha representación en el Teatro Imperial vienés, por lo tanto, podría haber sido antes de finales de mayo de 1872, pues en esta fecha muere la madre de su marido Francisco José, la archiduquesa Sofía de Baviera, tía-abuela de Luis II. El rigor y discreción del luto perduraría bastante, obligando el no poder ver espectáculos públicos hasta finales de ese mismo año, por lo menos. La segunda posibilidad, y creo que más factible, es 1873 (en el artículo de LIA, afirma con rotundidad este año y hasta da detalles: "la noche me dejó inolvidable impresión") de la dificultad de poder conseguir las entradas, aunque nos lo cuenta en LIA, 11/XII/1916. En el 73, la emperatriz está en Viena casi permanentemente, en Hofburg y Schönbrunn, sólo en noviembre se desplaza a Gödöllö. Me quedo con la representación del Holandés para 1873, a poder ser en su época más cómoda y primaveral-estival, la mejor estación y fecha para ver la Exposición Universal vienesa (1 mayo a 31 de octubre de este año y no del anterior... donde solo se podría comenzar, como mucho, su inicial montaje), aún no compuesta del todo, como ella bien nos dice.
} 
de Baviera, existía el germen del delirio estético, del sueño poético, casto, pero sin fundamento dentro de la realidad (LIA, 11/XII/1916).

Es una obra de transición, lo sabemos, pero no duda en demandar mucho más adelante en el tiempo, en 1914, una "temporada wagneriana en que nos den seguidas las obras del maestro, empezando por El Barco fantasma y acabando por Parsifal". No incluye al Rienzi, ya conocido por ella y que ve estrenar en el Real el 5 de febrero de 1876. Intuye, y muy bien, que la obra wagneriana y su Drama musical está ya en marcha, que tal vez el Holandés Errante es la determinada rebelión del poeta frente al músico, un elevado poema textual ${ }^{12}$ que todavía (aunque ya lo teoriza en su mente) no puede establecer en Rienzi, y así se decanta, en detrimento de la suerte del Último Tribuno, por la aún ópera (estrenada en Dresden, 1843) del defenestrado Holandés encantado:

Se Ilamaba la ópera Rienzi; yace en el olvido: era de estilo más bien italiano, y no gustó ni poco ni mucho. Medio siglo casi tenía que correr antes de que el wagnerismo dominase a la corte de los Felipes (LIA, 19/I/1914).

[sobre la "música del porvenir"] Y ya desde que regresamos a España (...) no volví a oír de Wagner media palabra [referencia al Barco Fantasma de 1873], hasta que el Real se atrevió a dar Rienzi, que no gustó gran cosa, ni había por qué, pues Rienzi, dentro de la obra wagneriana, carece de importancia, y hasta de originalidad, estando lleno de escuela italiana. Mucho tiempo tardó en aparecer con su cisne Lohengrin... (LIA, 21/XII/1914).

\section{Los lienzos pintados sobre el escenario del Buque/Holandés, que pudo haber visto} en Viena la joven promesa, pudieron ciertamente haber sido los que posteriormente

\footnotetext{
12 Y ello es así que al propio Wagner no se le acepta inicialmente su obra del Buque Fantasma y sí su libreto, sin música, en los tiempos parisinos de 1839. La dualidad del título de la obra Buque Fantasma (título inicial)/ Holandés Errante, viene dada por la necesidad, en penuria económica del compositor alemán, en 1841, de vender dicho título original y el guión argumental a Léon Pillet, éste encargará una ópera en francés a L.- Philippe Dietsch, Le Vaisseau Fantôme, relegada aún hoy en los repertorios mundiales. Richard se conformaría con cambiar el título por el definitivo Holandés Errante. El hecho lo relata con bastante detalle el mismo Wagner en su Mi Vida (edición nuestra in pp. 73-75). Quiere ofrecer precisiones Pardo Bazán cuando reflexiona y duda sobre el título: “...se titulaba Fliegende Hollander, o sea, en castellano, El holandés volante. Después, prevaleció el título de El barco fantasma" (21/XII/1914): se olvidaba. En otro artículo anterior (LIA, 6/III/1899), y tomando y citando como referencia la obra de Catulo Mendes sobre el Buque Fantasma (pensamos que de ahí la fijación para con ese título y no el otro, final), arremete y explica las dificultades económicas, extremas, que llevaron al autor a vender el título inicial. Las citas de Mendes son, “...el Buque Fantasma [a quien se lo vendió, L. Pillet y música de Ph. Dietsh, como sabemos], firmado por cierto autor dramático que no nombraré (...), y puesto en música por un compositor a quien es ocioso nombrar, porque nunca ha existido..."; luego seguirá ella, clara en sus disposiciones, "París, que desconoció a Wagner obscuro, negó, quiso cerrar el camino a Wagner glorioso ya; pero fue tan inútil como todo lo que se dirige al mismo fin, de pretender apagar astros. Soplaréis la bujía, extinguiréis el foco eléctrico aislando los hilos; con agua sofocaréis el fuego del horno..., pero a la inaccesible estrella no alcanza el soplo de nuestro aliento, ni el aire de fuelle manejado por manos envidiosas y coléricas. Wagner forma parte de la Vía Láctea”. La cita es casi para enmarcar.
} 
veremos en la autoría de Max Brückner (1901), y los que luego verá en 1896 (estreno en el Real, 27 de octubre), así los registra y analiza Juan Paz Canalejo (2006: 216$217)^{13}$, siendo los mismos, los artistas Giorgio Busato y Amalio Fernández, según el historiador de las "magias reales", seguro que muy parecidas a las de M. Bückner (v. Anexo Holandés Errante 1, 2 y 3), su clara referencia. José Subirá nos dirá el efecto de las pinturas de Busato y Amalio, con el atrezzo, que "En el Real produce el mejor efecto aquel grupo de tocas blancas de las hilanderas, con su corpiños y zagalejos de colores enteros y armoniosos (...) mientras que un sol poniente figurado del modo más realista posible, teñía de rojo las pálidas faces"14.

En contraposición a este optimista comentario, diremos con Juan Paz y J. Subirá que "En aquel estreno sensacional, el director timonel fue inexperto ante los escollos (...) al final de la obra, el buque del holandés no quiso hundirse en el abismo, lo cual destruía epilogales ilusiones (...) se habló más de esto que de aquel Wagner acogido con tantas reservas por timoratos críticos y aquel buque empañado en no naufragar cuando hubiera debido hacerlo para quedar bien con todos" ${ }^{\prime 15}$.

El mismo Wagner (Mi vida, p. 90), después del desastre del estreno del Holandés en Dresde (2/I/1843) toma nota del mismo y se promete meticulosidad en este aspecto:

El relativo fracaso de mi obra me señaló, en primer lugar, con qué meticuloso cuidado había de ocuparme en el futuro de la interpretación dramática de mis composiciones (...). Y en efecto, a pesar de la abominable vacuidad de la escena, la gran artista [Schröeder-Devrient, soprano] consiguió en el segundo acto cautivar por entero al público entusiasmado (...). En el tercer acto, el estrépito de la orquesta no consiguió agitar aquel mar que siguió en una estúpida bonanza, ni a mover el buque fantasma de su prudente posición.

El esmero necesario para el éxito de las representaciones wagnerianas ha de ser total, la coordinación arte plástica, música (voz y orquesta) y drama teatral de los personajes ha de rayar casi en la perfección. Es por eso que también, amén de las impresiones generales y musicales, incluso literarias sobre Wagner de Doña Emilia, no podamos nunca perder la perspectiva de un "Arte total" ya en marcha y perfectamente comprendido por la escritora: ver-observar justo lo que ella pudo haber visto en los telones pintados de los dramas musicales del Real (¿también del Teatro Principal coruñés?...en 1897 y $1907 . .$.$) . Por cada drama que comentemos, e$

\footnotetext{
13 Op. cit. Paz Canalejo.

14 Cfr. de Paz Canalejo, sobre J. Subirá, op. cit. p. 217. Igualmente los telones pintados y tramoyas de óperas como La Africana (su "barco basculante" de Busato, con ayuda de Ferri) o Trafalgar (G. Busato, en sus diferentes versiones y bocetos), bien pudieron haber influido en la puesta y escenografía del Holandés.

15 Cfr. de Paz Canalejo, sobre J. Subirá, op. cit. p. 218.
} 
iremos prácticamente obra por obra, hemos de darle "un telón de fondo" visual si lo podemos reconstruir.

Alrededor del Rienzi, los lienzos escenográficos debieron haber sido los inspirados por su estreno en Dresde de 1843, aunque ella lo vea en el 76. Los ítems de incidencia sitúan a estas dos obras (Rienzi, 4 y Holandés/Barco Fantasma, 5) en un número no mucho más inferior (e incluso superior) que obras de gran calado como el Tristán (5) o El Oro del Rhin (2): casi sin duda, la importancia de haber sido éstas las primeras obras que vivencia directamente le habrían impactado y ayudado mejor a recordar sus iniciales experiencias, tratándolas de una manera especial en su obra, especialmente el Barco Fantasma, como hemos percibido.

\section{LOHENGRIN (1881) Y TANNHÄUSER (1890): "LOHENGRIN, SIN DUDA, FUE LO QUE MÁS AYUDÓ A RECONCILIAR CON LA "MÚSICA ALEMANA" $^{16}$ (...) AL PARAÍSO DEL TEATRO REAL".}

La admiración. Gracias al excelente trabajo investigador de Paz Canalejo ${ }^{17}$, tenemos los telones pintados ${ }^{18}$, tramoya y vestuarios en fotografía del Lohengrin del acto primero, que vería la luz en el Real madrileño en 24/III/1881, en dicción italiana, y ensayada treinta y cinco veces antes de su representación, con Juan Goula en la batuta y ni más ni menos que Julián Gayarre como el caballero del cisne ${ }^{19}$; con iluminación a la última, venida de París, "con tres soles" ("uno en la sala, otro en la escena y el tercero en el foyer" ${ }^{20}$, distribuyéndose entre los espectadores un folleto explicativo: toda una novedad Ilena de magnificencia, aunque el "temor" sobre la

\footnotetext{
${ }^{16}$ La cita es de LIA, 19/I/1914, hablando del Parsifal.

17 Op. cit. p. 207, figs. 215-216.
}

18 No sabemos mucho de la escenografía, tramoya, utilaje y vestuario de esta versión, venida sin duda de la de Weimar (1850, de ella diría el mismo Wagner que "Carlos Ritter, que regresó pronto a Zurich, me habló de los defectos que había observado en la puesta de escena, y de un mediocre cantante..." (Mi Vida, p. 151), posiblemente inspirada en Max Brückner, y que el excepcional Mestres Cabanes representó de una manera magistral, de esta opinión es también Juan Paz (2006; p. 207-208), pero que a su vez provenían de la escuela de escenógrafos realista catalana: F. Soler i Rovirosa, M. Vilomara, F. Urgellès, J. F. Chia. Alarma, O. Junyent, R. Batlle i Gordó, A. Gual, etc. Recordaremos el acto I del Lohengrin de Vilomara, el de Cabanes ya lo reproduce J. Paz en el apéndice gráfico de su obra, lámina VI. También el mismo anexo, figura 5, la famosa fotografía del primer acto del estreno del Lohengrin madrileño (1881).

19 Lo hemos dicha alguna vez cuando hablamos de las comparaciones del "cuello císneo" de la emperatriz austríaca Sissí, o la reiteración estética del cisne en muchos comentarios del Lohengrin, o incluso dando un título a una de sus más importantes novelas, El Cisne de Vilamorta. En la Casa-Museo de Coruña (calle Tabernas, 11) podemos observar postales con detalles modernistas con el elemento cisne (su simbología de la bondad y pureza en el Parsifal...) en sus ilustraciones, una en especial, de clara estética wagneriano-modernista.

20 Op. cit. P. 206. 
larga duración de la sesión se fuera poseyendo poco a poco de determinados sectores del dubitativo público madrileño, también sin ayudar a la noble causa del éxito, la ausencia de Isabel II en el palco real, aunque se esperaba...

Se parece bastante la escenografía general que observamos, y ello nos cerciora de lo dicho en algunos casos -los anteriores del Rienzi y Holandés, pero también en posteriores- de la obligada referencia de las escenografías de los estrenos europeos (Weimar, 25/VIII/1850) para poder "rastrear" aspecto verdadero de lo que se pudo ver en esta representación el mismo día de su estreno, y en uno de sus palcos, la atenta mirada del público.

No fueron los peores años, ni mucho menos para Doña Emilia, que ya ve en 1881 su Un Viaje de Novios, suponemos ya muy próxima en su mente La Tribuna, el inicio de su consagración. En su imaginación dramático-musical, también tiene un hueco el ya consolidado Caballero del Cisne, como tiene a bien Ilamarle; las referencias $(12+3,15$ total, v. cuadros 1 y 2$)$ sobre nuestro referenciado héroe, son las más numerosas de todas la piezas wagnerianas y sin duda, una de sus obras predilectas: solo las noticias sobre la persona y obra en general de Wagner le superan en ítems (26), e igualan a sus citas sobre la mitología y leyendas germánicas (12).

Veamos cómo se trata con este ya espectacular, plenamente (aunque inicial) drama wagneriano, habiendo visto anteriormente la referencia a nuestra obra en Por el Arte, comparando a Lohengrin con el rey Luis II (LN, 1/IV/1912), en una dura e irónica crítica a su mala puesta en escena en 1905 (LIA, 27/II/1905)...y el cisne de un Lohengrin "salvador" de la calidad que tal vez las primerizas obras no cotejaban (LIA, 21/XII/1914), el castizo madrileño amante del Lohengrin y Tannhäuser (VPE/APTE, $1889)^{21}$, aunque ahora mismo exponemos otras citas de no menor interés:

[repasando los orígenes legendarios y mitológicos de las obras] Las leyendas y viejos poemas del caballero del Cisne, dieron origen a Lohengrin. (LIA, 19/I/1914).

[predilección por la obra wagneriana sobre la italiana, con Lohengrin como referente] Se cuenta con La Walkyria y aparece Carmen; se espera Lohengrin y salta La Africana; se anuncia Gonzalo de Córdoba y se cae en buena Sonámbula... Lo peor de todo, que nunca es mudarse por mejorarse. (LIA, 20/III/1899).

[relaciona directamente el Lohengrin con el Parsifal, a través de las leyendas de Monsalvat] El Grial, el símbolo de los símbolos, me ha evocado las desventuras trágicas de sus custodios y defensores. Y mientras la frase honda y patética del Lohengrin y las lamentaciones de Amfortas gimen en mi alma, pienso que los Templarios han sido bien vengados... (LIA, 20/XII/1909).

\footnotetext{
21 Curiosa reseña, porque en otro comentario sobre los paisanos gallegos y su música popular, compara lo natural de la música rural de los "cantos del terruño", con los coros del Real y ensayos del Lohengrin, para colocar cada cosa en su sitio y como sana complementariedad (VPE/FyA, 1889, p. 414).
} 
[comprensión de la obra]...en el no corto tiempo que llevo de asistir al Real asiduamente, he podido convencerme de que son contadísimos los espectadores que se enteran de los argumentos de Wagner (el del Lohengrin entre ellos), y que ni aun teniendo en las manos ese librito que cuesta diez centavos, o ese periódico-anuncio que se da gratis...(...), entienden lo que significa todo aquello del "raconto", ni el sentido de la fatídica frase del paladín: "No intentes averiguar de dónde vengo, ni como me llamo (LN, 17/I/1910).

[la españolidad del Lohengrin y Parsifal sobre los que las consideran "foráneas"] Así es que produje gran sorpresa a un admirador impenitente de Sonámbula, al decirle que Lohengrin era punto menos español que El Trovador, y que Parsifal se funda en algo tan exótico...como la misa (...) referíame a mi convicción antigua de que el castillo de Monsalvato, donde se conserva la copa "descendida del cielo" que custodian los caballeros del Santo Grial, está en España, si es que podemos localizarlo en alguna parte (LN, 17/I/1910).

[sobre el estreno del Lohengrin] Algo achicados andan los que declararon a Wagner "rey de la Lata" cuando se estrenó Lohengrín [sic]; pero aun cuando el wagnerismo se ha desarrollado, se ha impuesto y ha conquistado a los concurrentes del "paraíso", las localidades altas, que acaban siempre por hacer la ley quedan, en las localidades bajas, partidarios de la música italiana, no porque no obliga a fijar tanto la atención como la otra.... (LN, 27/XII/1913).

La narrativa corta literaria ha sido un feliz soporte donde el Lohengrin ha destacado con especial incidencia, el cuento El Disfraz (1909) lo sitúa como un sueño que toda melómana, sencilla (una modesta institutriz de música de una niña bien acomodada) pretende, un anhelo difícil de conseguir, incluyendo la distinción y etiqueta social (de hecho, una aspiración de ascenso) que conviene para ir a una butaca del Real. La autora opta por el arte en estado puro ante las convenciones sociales:

...vamos a ver ¿no tiene usted muchas ganas de oír Lohengrin? (...)

- Yo... ¡Lohengrin!¡Ya lo creo señora! -prorrumpió de súbito, en involuntaria efusión de un alma que hubiese podido ser artista si no fuese de madre de familia obligada a ganar el pan de tres chiquitines - ¡Ya lo creo! Sólo una vez oí una ópera..., ¡Y hace tantos años ya! ¡Y Lohengrin! Se dice que lo cantan divinamente...

- ¡Oh! ¡Ese Capinera! ¡Y la Stolli! ¡Si es un bordado! Bueno; pues se trata de que esta noche tenemos dos asientos...

- (...) Agradezco tanta bondad, y disfrutaría mucho oyendo ópera, que no conozco sino en papeles...; pero ni mi esposo ni yo tenemos ropa...como la que hay que tener para ir a las butacas del Real. (El Disfraz, pp. 262-263, v. bibliografía)

Sin embargo, es en la novela Dulce Dueño $(1911)^{22}$, ya en su etapa modernistaespiritualista avanzada, donde el dolor da acceso a la vida espiritual, donde la música (directa al hombre interior, como los personajes wagnerianos) y los ideales cristianos son capaces de cristalizar en la protagonista Lina, un momento de ascesis

22 La edición estudiada de esta obra de E. Pardo Bazán es la de Marina Mayoral, ed. Castalia, Madrid, 1989 (v. bibliografía). 
tremendamente sentido y original, y hasta hay claridad de atisbos para hacer una crónica operística a su estilo:

Oír música, tal vez provoque en mi sensibilidad irritada y seca la reacción del Ilanto. (...) hincando la barbilla en el pecho y volando los ojos con escandalizados párpados -me agazapo en el mejor sitio y escucho, extasiada ya de antemano, la sinfonía de Lohengrin.

Nunca he oído cantar una ópera. Mi frescura de sensación tiende un velo brillante sobre las mil deficiencias del escenario. No veo las tosquedades del coro, las coristas de la senectud (...); los coristas sin afeitarse (...); todo lo que, a un espíritu gastado, le estropea una impresión divina. Tengo fortuna de poder abstraerme en las delicias del poema y de la música. (p. 150).

Catalina Mascareñas es un personaje de difícil tamiz, una persona que intenta decidirse entre una sensualidad refinada y un camino que al final (¿también al principio?) aparece como decididamente espiritual, un ideal cristiano (sin duda influenciado por la hagiografía de Catalina de Alejandría) a seguir, debatiéndose entre sus aspirantes a llevar una vida "normal", desde el círculo femenino de una óptica que camina a un "Amor ideal"; también, no lo puede evitar, se describe la puesta de escena (luces, vestuario, tramoya, cantantes...) y la sensación musical en un todo sublimado,

Con sugestión misteriosa, la frase mágica se apodera de mí. "No intentes saber quién soy... No preguntes jamás mi nombre..." Así debe ser el amor, el gran adversario de la realidad (...). Deslizándose por la corriente sesga de un río azul, su navecilla císnea le traerá, a luchar nuestra lucha, a vencer nuestras fatalidades. Le tendremos a nuestro lado sólo una noche, pero esa noche será la suprema (...), aunque muramos de dolor, como Elsa de Brabante, habremos vivido (...).

El preludio acentúa su magnífico crescendo. Saboreo el escalofrío del tema heroico que vibra en sus notas (...). El caballero desembarca, entre la mística emoción de todos, de Elsa palpitante, de Ortruda y Telramondo estremecidos de pavor. Avanza hacia la batería, y yo me ahínco en la barandilla del palco para mejor verle. [foto de un Lohengrin del siglo XIX a continuación] ${ }^{23}$

Es una especie de arcángel, todo encorazado de escamas, en las cuales riela, culebreando, la luz eléctrica (...) ¡Qué miedo sentía yo de ver salir un Lohengrin caricaturesco! No, por mi ventura grande, Ilámase Cristalli (...) Rasurado, con los suaves tirabuzones rubios de la peluca, simulando el corte de cara juvenil, se le atribuirían de ventidós a veinticinco años, pero la viril muñeca y el cuello nervudo acusan más edad (...) Lohengrin no es el héroe niño, como Sigfredo. Es el paladín; puede contar de veinte a cuarenta (...). El tema del silencio, del arcano, vuelve, insistente, clavándose en mi alma. "No preguntes de dónde vengo, no inquieras jamás mi nombre ni mi patria..." ¡Así se debe amar! Mi alma se electriza. Mi vida

\footnotetext{
23 Esta foto de finales del XIX, bien pudiera servirle a nuestra escritora como inspiración del cantante Cristalli, véanse los detalles del vestuario, incluido el "encorazado de escamas, en las cuales riela, culebreando, la luz eléctrica” (Dulce Dueño). Fotografía del tenor Ernest van Dyck (1861-1923), contemporáneo de E. Pardo Bazán, con la cantante (creemos) Fidès Devriès.
} 
anterior ha desaparecido. No siento el peso en mi cuerpo. ¿Quién sabe? ¿No existe, en los momentos estáticos, la sensación de levitación? ¿No se despegará nunca del suelo nuestra mísera y pesada carne? (pp. 151-152).

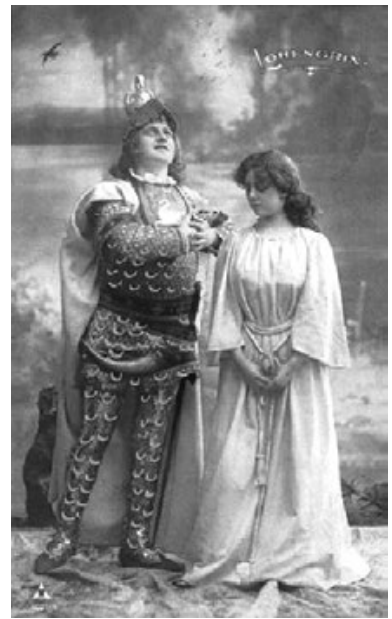

Poco más podemos decir de una oyente y espectadora cuando percibe, entiende y siente lo que escucha, ve e interpreta, creo que la ya Condesa, en sus años de creación narrativa, más que avanzada y madura, nos expone el sentimiento wagneriano con una calidad tan excelente que casi no tenemos mucho más que añadir (iy hasta coincidir en muchos aspectos!) si queremos describir lo que realmente se experimenta en una audición y contemplación de una obra wagneriana. Así, como con el Lohengrin, especialmente con su caballero, no lo volveremos a ver escrito de la pluma de Pardo Bazán.

Pero falta Elsa von Brabant. No sale muy bien parada la joven de alta cuna y hermana de Gottfried (el cisne del caballero "encorazado en escamas" y que acompaña al enviado a través del río Escalda), pues ésta se aferra al espacio mundano que Lina, desde ahora, ya no teme y hasta desprecia por vulgar:

La necedad de Elsa, empeñada en rasgar el velo, me exaspera. ¿Saber qué? ¿Una palabra, un punto del globo? ¿Saber, cuando tiene a su lado al prometido? ¿Saber, cuando las notas de la marcha nupcial aún rehílan en el aire?.

Yo cerraría los ojos; yo, con delicia, me reclinaría en el pecho cubierto de argentinas escamillas fulgurantes. "Sácame de la realidad, amado... Lejos, lejos de lo real, dulce dueño..." Y en efecto, cierro los ojos; me basta escuchar, cuando el raconto se alza, impregnado de caballeresco desprecio hacia el abyecto engaño y la vileza, celebrando la gloria de los que, con su lanza y su tajante, sostienen el amor y la virtud...Lentamente, abro los párpados. Los aplausos atruenan. Dijérase que todo el concurso admira a los del Grial, sueña como yo la peregrinación hacia las cimas de Monsalvato...Quieren que el raconto se repita (...) La pasión íntima que late en el raconto, aquel ideal hecho vida, me corta la respiración: hasta tal punto me avasalla. Anhelo morir, disolverme; tiendo los brazos como si llamase a mi destino...apremiándole. Imantado por el sentimiento hondo que tiene tan cerca, Lohengrin alza la frente y me mira. Fascinada, respondo al mirar. Todo ello en un segundo. Un infinito.

"Brabante, ahí tienes a tu natural señor..."

Lohengrin ya navega río abajo en su cisne simbólico. Le sigo con el pensamiento. Vuelve hacia la montaña de Monsalvato, al casto santuario donde se adora el Vaso de los elegidos, la milagrosa Sangre. Allí iré yo, arrastrándome sobre las rodillas, hasta volver a encontrarlo. Yo no he sido como Eva y como Elsa; yo no he mordido el fruto, no he profanado el secreto. A mí podrá acogerme el caballero de la cándida armadura y murmurarme las inefables palabras... (pp. 152-153) 
Aunque Lina, en un presente omnisciente afirma que "nunca he oído cantar una ópera" o "mi frescura de sensación" ante este Lohengrin literario y a la vez tan vivido y sentido, la verdad es que la experiencia de la autora como aficionada es fuente de las mejores sensaciones, y éstas, creemos son las verdaderamente vividas por nuestra Lina-Emilia...y se nota. La realidad es que la heredera de Mascareñas está verdaderamente informada sobre el mundo wagneriano: compara al caballero Lohengrin con Sigfrido (más "héroe niño") optando por la veteranía y madurez del primero; conoce el ciclo literario, simbólico-espiritual y estético del Grial (su Vaso, su Sangre, la Redención) ${ }^{24}$, el lugar del Monsalvat, la custodia de los "caballeros heridos", en un intento de erudición, que ya desde ahora, diremos, nuestra autora unifica el personaje del hijo, con los ambientes de su padre, Parsifal.

Singularidad sin par, y no podíamos dejar al paso, es el tema de la reivindicación de españolidad del drama Lohengrin (hará lo propio con Parsifal, como se verá más adelante):

Cuando este año me digan que no entienden el exótico argumento de Lohengrin, y que el "racconto" famoso debe cantarse en italiano y nunca en castellano, podré exclamar con nuevo fundamento: "Pues Lohengrin es poco menos español que el Trovador, y los caballeros del Grial hablaban nuestra lengua, y el maligno encantador Klingsor, el del jardín prodigioso, también puede que fuese aragonés o catalán (LN, 17/I/1910).

Del Teatro Real a una Coruña finisecular. Va siendo hora de volver, aunque sea de paso, a lo que pudo ocurrir en el Teatro Principal (el "Coliseo de San Jorge", restaurado desde inicios de los años 80) de Coruña en la semana primaveral que terminaba el domingo 30 de mayo de 1897, cuando sale publicada una crónica que remitiremos. A finales de mayo ${ }^{25}$, se representaron aquí La Traviata verdiniana ("conocida hasta la

${ }^{24}$ Reincidirá en el tema del Grial en Dulce Dueño en las páginas de nuestra edición: “...Si tú quisieses, dulce Dueño, yo te ofrecería licor para refrescar de tus cruentas llagas...Yo te daría con qué renovar el Grial", p. 280; sobre el Lohengrin de nuevo, "Le refiero todo, en abreviatura, desde los fugitivos ensueños el caballero Lohengrin, hasta la vista del médico...", p. 216. Otros temas que abarca esta interesante para nosotros, novela pardobazaniana tardía, son: Sentido superior/goce/cultura: pp. 79, 144, 157, 171-172, 202-203, 218, 246/256, 281-282. Gemelos de teatro: 122. Culto a mi persona: 124, 126, 127-128, 130/132, 178-179, 275, 266. Hidalguía: 135, 141, 146, 265. Música-Lohengrin: 150/154, 216. Mujer diferente: 266/269, 158, 168. Rin, río leyenda: 232, 233.Felicidad/amor ideal: 32, 216, 224. Farnesio “Hans Sachs": 142, 145/147. Grial: 280 pp.

25 X. Manuel Carreira en "El primer encuentro coruñés de Amina y Lohengrin", LIII Festival de Ópera de A Coruña”, pp. 57-70, afirma que esta inusual temporada operistica de 1897, "ofreceu aos coruñeses sete títulos que foron representados en italiano en varias ocasións ao longo do mes de maio: La Favorita, Sonámbula, Faust, Carmen, Lohengrin, Carmen [sic], Cavalleria Rusticana e Pagliacci. Os cinco últimos títulos protagonizados por un trío de auténtico primo cartello (...). A orquestra do Teatro Principal foi dirixida aquela tempada polo mestre Vehíls". P. 57-58. Fuera de temporada regular y posiblemente aprovechando la presencia en nuestra ciudad de Ignacio Tabuyo (barítono, 1863-1947) y su prestigiosa compañía, los principales papeles de este Lohengrin se dieron con referentes importantes como Alfonso Garulli (tenor, 1857-1915) y Ernestina Bendazzi-Garulli (soprano, 1864-1931). 
saciedad la primera" afirma Orsino- Galo Salinas Rodríguez- en Revista Gallega ${ }^{26}$ ), Lohengrin , I Pagliacci de Leoncavallo, entre otras. No sabemos a ciencia cierta la presencia, escucha y visualización de Emilia Pardo Bazán ${ }^{27}$ en el primer (que nos conste $^{28}$ ) Lohengrin integral de Coruña en la primavera de 1897. La prensa de que disponemos nos informa, primeramente en La Voz de Galicia (21/V/1897, viernes):

Para mañana está anunciado Lohengrin. Esta noche se celebrará el ensayo general de dicha obra. La Empresa fijó ayer en varios sitios del teatro carteles rogando a los abonados que se abstengan de concurrir a dicho ensayo. No se permitirá, pues, la entrada en el teatro. La determinación es muy acertada

La primera representación wagneriana, sin duda cantada en italiano, es del 22 de mayo, sábado, y la repercusión en el público y ciudad coruñesa es notoria, en La Voz de Galicia se constata y aprecia la importancia del evento por el cronista Fusa (de suponemos igual autoría en las restantes reseñas de este periódico, donde no figura explícitamente), amén de una "buena guía" introductoria de audición a tal efecto:

Es para nosotros un sueño que en el teatro de la Coruña pudiera hacerse una obra de Wagner. Ese sueño se ha convertido en realidad. Anoche se puso en escena en el coliseo de San Jorge una de las más hermosas obras del gran maestro alemán; se cantó Lohengrin y esto debe consignarse como un gran acontecimiento artístico de importancia suprema en los anales del teatro de la capital de Galicia (...) De aquí que se haga fácil comprender como para Wagner no hay prima donna absoluta y otra porción de cosas más, pero sí personajes de una acción dramática. Esto se ve en el Lohengrin, una prima donna-mezzo-soprano contralto, que está callada casi todo un acto, Ortruda [en dúo con Tabuyo] (...) Por último, el racconto del último cuadro es una melopea conceptuada como una de las páginas musicales más bellas que se han escrito, así como la escena de la despedida, que es condensación y resumen de las ideas desarrolladas y de los sentimientos expresados en todo el curso de la obra (...) De la interpretación dada anoche a ésta, diremos que la señora Bendazzi y el señor Garulli, maestros del arte del canto y conocedores como pocos seguramente de la manera de decir la música de Wagner, estuvieron a inconmensurable altura. El público les ha hecho anoche salir al palco escénico

26 Revista Gallega, año III, nº 117, 30/V/1897, pp. 5-6.

27 El estreno en el Teatro Real de Madrid, al que seguramente ya había asistido nuestra cronista es, lo sabemos, de 24/IV/1881.

28 En Revista Gallega, dirigida y comentada por Galo Salinas Rodríguez, "Orsino” como firma de crónicas musicales y teatrales, en el número 114 de 9 de mayo de 1897, leemos, hablando de una Favorita, (elección desafortunada según él como obra inaugural) con el matrimonio Garulli-Bendazzi como intérpretes “...pero después de haber escuchado los enérgicos giros del Tannhäuser, Otello, Lohengrin y otras obras que hoy son aceptadas con agrado por todos los públicos ya encauzados por las márgenes del modernismo" (p.5). Es decir, o sólo el mismo Orsino y sus allegados ya habían escuchado en otras latitudes las obras comentadas, o el mismo Principal y su público ya habían corrido el telón para las primeras obras wagnerianas de la ciudad herculina, toda una sorpresa si así fuese. Tal vez, y es una suposición, ya se habrían interpretado oberturas y fragmentos de la obra en galas y repertorios variados, pero no su representación íntegra sobre el escenario, sería lo más lógico. 
innumerables veces entre bravos y aplausos (...) el duetto de amor, que cantaron como ángeles, sobre todo, les valió una ovación delirante (...). Ortruda estuvo muy trabajadora, y recibió también aplausos en el dúo con el señor Tabuyo [papel de Federico de Telramund]. Este, como siempre, aplaudidísimo: lo mismo que el señor Waltter. Los demás artistas cumplieron; pero los coros, ni aún esto.

La orquesta muy bien [maestro Wehils] (...) El preludio fue repetido entre atronadoras salvas de aplausos.

La ópera fue puesta con lujo, así las decoraciones como el vestuario, Ilamando unas y otras la atención.

Enviamos nuestra felicitación más entusiasta a los artistas, felicitándonos a la vez que hayamos podido oír en nuestro teatro obra tan hermosa, que seguramente proporcionará a la empresa llenos como el de anoche, que era completo. Hoy segunda audición del Lohengrin. (La Voz de Galicia, 23/V/1897)

El éxito de Lohengrin en Coruña, se aprecia, fue rotundo y se refleja en el texto y en la ciudad, pues además de la vinculación de su propio autor, podría ya entonces existir un núcleo de admiradores por la obra de Wagner, considerable... Pero, ise podría haber perdido Doña Emilia, este esencial evento en Coruña como buena aficionada a la lírica y a Wagner en especial, sobre todo, resaltando la importancia de semejante estreno para una ciudad como Coruña? Pensamos que no.

Esta especial temporada de mayo de 1897, junto con nuestro Lohengrin (a saber, en dos sesiones, 22 y 23 de mayo), contó, decíamos, con otros importantes títulos (con varias representaciones cada una, de las que desconocemos el número, aunque podemos rastrear el estreno que pondremos entre paréntesis a continuación) que también fueron reseñados por el cronista de La Voz y fueron: La Favorita (inaugural, ¿2 domingo?), Cavalleria Rusticana (6 jueves), Fausto, Lucía de Lammermoor (20 jueves), Sonámbula (20 jueves), La Traviata (25 martes) y I Pagliacci (26 miércoles). Es posible que se interpretase Carmen $^{29}$, al menos en perfomances de galas líricas y no completa ni representada.

No se ha olvidado Orsino en Revista Gallega de la trascendencia del Lohengrin en Coruña, y en un trabajado comentario suyo sobre la recientemente acabada temporada operística, no acaba de recuperarse de lo que escuchó hace pocos días en el coliseo del Principal:

El Credo cristiano y la mitología escandinava uniéronse para dar forma material a un ser y del heterogéneo consorcio resultó la monstruosidad imaginada por el revolucionario Wagner (...). Y surgió Lohengrin. Y el genial maestro amalgamó desconcertadas melodías.

\footnotetext{
29 Es contradictoria la opinión de Orsino quejándose (Revista Gallega, 9/V/1897) de la no inclusión de Carmen en la edición operística de este año 1897, o por lo menos no ser ésta la obra inaugural y no La Favorita, como así aconteció. Puede ser, no obstante, que se representase más tardíamente, ya que en su misma revista (30/V/1897), al elogiar a la pareja Garulli-Bendazzi, agradezca a éstos sus interpretaciones en Cavalleria Rusticana, Carmen, Lohengrin y Pagliacci, ergo...
} 
Y la melancólica y sentimental música de los inspirados Bellini, Donizzetti, Verdi y Rossini refugióse en el santuario de las almas candorosas, atemorizada de la bizarría con que en son de conquista invadió sus feudos la dominadora avalancha de los Tannhäuser, los Nibelungos, Parsifal, Maestros Cantores y Lohengrin (...).

El desempeño de la obra ha sido admirable (...). La obra fue representada con lujo así en la indumentaria como en el arreglo escénico, por lo que se truecan en alabanzas las censuras que dediqué la semana anterior al director de escena, quien de desear es que en todas las obras tenga igual acierto. (Revista Gallega, 30/V/1897).

Todo el artículo es una disertación-justificación de lo sublime que es la ópera italiana (y francesa, añadiríamos), de "bellísimas cadencias", no aceptando que la música "científico-filosófica" de Wagner pretenda "sepultar en el pasado lo que aún es del presente", ergo, "prefiero lo antiguo con sus gastados moldes a lo moderno con moldes nuevecitos y relucientes". El debate, ya se sabe, estaba servido.

¿Pero dónde estaba la escritora gallega en aquella primavera finisecular? Veamos. Durante este año de 1897, sabemos que asiste al Ateneo madrileño a finales de enero $^{30}$, que acaba de redactar dos novelas, El saludo de las brujas y El tesoro de Gastón, dando continuidad a La Esfinge y La Quimera, de la cual hemos venido comentando. Según el libro biográfico de Eva Acosta $^{31}$ (2007: 412-413) tiene ahora, en general, "mala salud", partiendo de un inverno infructuoso en el cual ha estado "seis meses sin escribir", aunque de labor intensa (2007: 417). Contando con sus ya habituales desplazamientos (por lo menos dos días de desplazamiento Madrid-Sada) a Galicia y a su pazo en la Granja de Meirás (Sada, A Coruña), cuando mejora el tiempo primaveral, leemos en el periódico madrileño El Día (5/V/1897) en la sección de "Sociedad":

Ayer salió para sus posesiones de Meirás (Coruña) la insigne escritora doña Emilia Pardo Bazán, acompañada de sus hijos y de su señora.

La hemos localizado, pero también es posible que a finales del mismo mes de mayo pudiera ya no estar en A Coruña, o bien que ese delicado estado de salud que le ha acompañado todo el año le hubiese impedido asistir al acto wagneriano del Teatro Principal, siempre y cuando estuviese informada desde el retiro de A Granxa. En fin, es muy probable que asistiese al estreno o siguientes sesiones del Lohengrin, pero ella no nos lo ha ratificado formalmente en escrito alguno que pudiésemos conocer.

\footnotetext{
30 Leemos en El Imparcial de 27/I/1897: "Hay «días de moda», en que el público del Ateneo parece el público de un primer turno del Real. Son estos días aquellos en que la autora ilustre de La cuestión palpitante, sencillamente vestida de negro, sube a la cátedra para dar sus lecciones de literatura. La gente les llama "los lunes clásicos del Ateneo".

31 Acosta, Eva (2007), Emilia Pardo Bazán. La Luz en la batalla. ed. Lumen, Barcelona.
} 
Ya mucho más difícil, y esta vez sin referencias de prensa, es la presencia de la viuda intelecta en el estreno del Tannhäuser ${ }^{32}$ en la Coruña de entre el 27 sábado, 28 domingo y 30 martes, de abril del año 1907. Está en Madrid, en concreto nos dice El Imparcial (25/IV/1907), sección de "Reuniones y Sociedades", que

Anoche tuvo lugar en los salones del Centro Gallego la distribución de premios a los alumnos del mismo. El acto resultó brillante. Pronunciaron elocuentes discursos los Sres. D. Ramiro Suárez y D. Eduardo Vicenti y la eximia escritora doña Emilia pardo Bazán, que ocupaba la presidencia.

En 1907, la eximia novelista reedita sus Obras completas con Un viaje de novios, un cuento como El fondo del alma (Cuentos del terruño), y ya para finales de este verano, aparece en una velada-homenaje a Concepción Arenal organizada por el Círculo de Artesanos coruñés, acto que se realizará en el Teatro Principal un 30 de agosto; la víspera se organiza una comida en su pazo de Meirás. Es un año de proposiciones para doña Emilia, pues desde 1906 ya ocupa la cátedra en el Ateneo madrileño en su sección de literatura y en la Universidad Central de Madrid, ejerciendo polémica cátedra de literaturas neolatinas.

Aunque avanza en la redacción de obras como La Quimera, La Sirena rubia, La Esfinge, La Sirena negra y El Dragón, nos cuenta Eva Acosta (2007; p. 493) que este 1907, la autora "apura el plácido tiempo de otoño en Meirás". Pero no en los abriles.

Es una pena, porque se habría encontrado nuestra escritora, sorprendida gratamente por ese núcleo wagneriano de San Jorge que incluye en sus comentarios el columnista de La Voz de Galicia (28/IV/1907, domingo), veamos,

Para hoy se anuncia por segunda vez Sonámbula. Veremos que dice el público.

El lunes nos dicen que vuelve a cantarse Tosca y valga por lo que valiere protestamos en nombre de muchos abonados. Se ha pedido Tannhäuser y alguien apunta que no se hará por indicación del maestro Villa. No lo creemos, conociendo sus amores por esta ópera y los afanes que le costó ensayarla.

El beneficio de este amable maestro, prematuramente celebrado a principios de abono -cosa insólita- sabido es que con Tannhäuser iba a anunciarse. Pero en fin, ¿quiere la empresa abrir, en la duda, un nuevo plebiscito, aunque sea pour rire? Creemos que triunfan los wagnerianos.

\footnotetext{
32 Este Tannhäuser tuvo bajo su batuta al maestro Ricardo Villa y la orquesta del Teatro Principal, siendo sus intérpretes, Luisa García Rubio (doble papel en Venus y Elisabeth), Colazza como Enrique, Blanchart como Wolfram, Sabellico (¿papel?), "la orquesta y coros excelentemente, y la empresa recibiendo plácemes de la asamblea" (Revista Gallega, 28/IV/1907, p. 5, crónica de Nelusko). En La Voz de Galicia (30/IV/1907), la crónica de Fusa (¿?), hay más pasión como veremos.
} 
Es más que simbólica una despedida del "Hidalgo de Tor" (no creemos que fuera ya el tal "Fusa" de hacía unos años) también redactor desde La Voz, en una interesante conclusión sobre la temporada de este año 1907:

Ayer, por vez tercera, Tosca, de Puccini. Pedían los abonados, pedían los críticos -imenudos críticos que no han arribado a esta pequeñez!-, pedían los aficionados que se cantase Tannhäuser. Y la empresa, Tosca. Cierto que en el pecado Ilevó la penitencia. El teatro, anoche, estuvo casi vacío. Más gente asiste a un ensayo. Hagamos resaltar la cultura, la gran cultura de un público bonachón, que aún ayer, para exteriorizar su natural disgusto, se mantuvo dentro de los correctos límites. La protesta fue sólo contra la empresa, buen rato después de haber caído el telón (...) $\mathrm{Ni}$ siquiera valió para congraciarnos con Tosca (que artísticamente queda a salvo) la carcajada de última hora contra la música y contra las cosas de Wagner.

Esta noche hay un delicioso poupurrit que despierta interés: un acto de Lucía (el primero); la obertura y el acto tercero de Tannhäuser, y otro acto de Barbero. (La Voz de Galicia, 30/IV/1907, martes).

[ La Voz de Galicia, en el mismo día 30, pero en diferente sección, a modo de "despedida"; firmaría "El Hidalgo de Tor" (i?)] Yo confieso ingenuamente, candorosamente quizá, que de la temporada toda, eso solo -Orfeo y Tannhäuserserá lo único que quede vivo y perdurable en mi recuerdo. Sin embargo esta noche es varia y solemne (...) Y luego, entrándonos por los campos umbríos y siempre lozanos del aria, escucharemos otra vez las estrofas inmortales de Wagner, el milagroso (...). (La Voz de Galicia, 30/IV/1907, sección "Del Teatro. Despedida").

[Hablando de la gala lírica del 30, martes, con fragmentos y acto tercero del Tannhäuser] Un Ilenazo. El teatro brillantísimo, rebosante. Desde las cinco de la tarde había público en las "alturas". El famoso cartelito de "no hay localidades" apareció en la taquilla una vez más (...).

La soberana obertura de Tannhäuser a punto estuvo de ser repetida. ¡Ay, sabe Dios cuándo podremos volver a oirla! (...) el tercer acto de la misma admirada ópera supo a gloria. Caigan nuestras lamentaciones trasnochadas sobre quienes no nos dieron el gustazo de saborear de nuevo por entero la obra. Colazza y Blanchart notabilísimos (...) La señorita García Rubio, aplaudidísima en la plegaria. Tannhäuser fue musicalmente, artísticamente la nota más admirada de la fastuosa velada de anoche. (La Voz de Galicia, 1/V/1907, miércoles).

Más pasión y admiración por las versiones del caballero del Wartburg y su santa amante, en la capital gallega, no se pueden pedir para el ambiente social y cultural posbélico español y coruñés (pues la guerra de Cuba y sus consecuencias también "Ilegaron" aquí). Ahora el columnista Nelusko, de Revista Gallega, resulta más comprensivo y tolerante para con las representaciones del Tannhäuser, veamos el cambio de posicionamiento, más sereno, aunque tenga que iniciar su reseña con ciertas afirmaciones en las que se detecta la mano de Orsino (coinciden los admirados compositores italianos de 1897, por ejemplo...):

Admiremos a Mozart, a Beethoven, a Wagner, mas no releguemos al olvido a Bellini, a Donizetti, a Rossini, comprendiendo en nuestro grato recuerdo al sublime Verdi (...). Tannhäuser fue el primero de los acontecimientos de la última 
semana teatral. (...) No puede darse más gracia, gentileza y elegancia de las que concurren en la simpática soprano Luisa García Rubio, al copiar los papeles de Venus y Elisabetta (...) Villa, el gran director, hecho un coloso agigantándose en la gradación artística.

La bellísima música de este poema sinfónico es una maravilla que el público saboreó (Revista Gallega, nº 631, 28/IV/1907)

Volvemos al Real. El caso es que Tannhäuser abre sus cortinones un 22 de marzo de 1890 (ya lo había hecho en Dresde, 19/X/1845, y en el Liceu en 1887) en el regio coliseo de Madrid, dándose varias representaciones y una participación de público asombrosamente indiferente (Paz Canalejo, 2006: 210-211), "Madrid tenía en Madrid su círculo de iniciados y legión de detractores".

Los escenarios pudieron ser pintados por G. Busato ("La Gruta azul de Capri") para el acto $\mathrm{I}^{\circ}$, escena $1^{\mathrm{a}}$, con la gruta de Venus como tema ${ }^{33}$. Para la segunda escena, un valle primaveral, usando al mismo tiempo como fondo el castillo del Wartburg, aunque se cree que este telón pintado ("fresco, florido, ameno" en palabras de Wagner) se usó doblemente para también el acto III, que le tocaba en otoño...El acto II es en salón principal ("el hall del torneo poético" que se debía semejar a un estilo de la época de Carlomagno) del castillo del Landgrave de Turingia, homenajeando un Certamen de Poesía y de bienvenida a Heinrich ante la alegría de Elisabeth, finalmente su redentora: se usó para tal ambiente una sala de ambiente renacentista, tal vez no muy apropiado, aunque solemne en vestuario y tramoya.

Los temas que Pardo Bazán saca a relucir sobre el trovador bipolar en algunos casos ya los hemos expuesto, ahora son los estos los que seleccionamos:

[aceptación en el ambiente general operístico del Lohengrin y Tannhäuser, aunque sospecha de la reacción ante otras obra de mayor calado] Y así y todo es de esperar que Wagner triunfará en el "regio coliseo" como ha triunfado ya en los conciertos. Llegará a oírse la tetralogía como se oyen Lohengrin y Tannhäuser (LIA, 6/II/1899).

[vinculación del Grial con el torneo poético del Wartburg] La idea del Grial se quintaesencia en Wolfrango de Esenbach, el gran minnesinger, vencedor en el torneo de la Warburga (LIA, 20/XII/1909).

[el tema de la obra, de origen popular] Tannhäuser es una superstición popular, cuyo origen se remonta a los tiempos en que las tribus bárbaras recibieron el cristianismo: un templo dedicado a Venus, y convertido como otros muchos en santuario cristiano, lo cree el vulgo sencillo habitado por el ídolo antiguo, encarnado en el demonio de la sensualidad, Venus, que encanta en su cueva a uno de los minnesinger del certamen de la Wartburga (LIA, 19/I/1914).

\footnotetext{
33 Que se usó la Gruta de Venus para tal Venusberg es constatado en un artículo de LIA (27/II/1905) que en algún momento hemos citado en LIA, 27/II/1905. (v. apartado 1. Wagner y sus obras en la crítica musical y texto literario de E. Pardo Bazán).
} 
[problemas de conciencia, cristianismo, Elisabeth/Santa Isabel] Los problemas de nuestra conciencia están simbolizados en la infernal tradición del Venusberg, con la diablesa que pierde a los hombres, en el certamen de la Wortburga [sic], en la figura célica de Santa Isabel, y surge de esta evocación el poema del pecado y del arrepentimiento, el milagro y el perdón (LIA, 21/XII/1914).

No se prodigan, por tanto, los comentarios a nuestro turingio trovador como sí se van a incrementar en otras obras que veremos; no obstante, las referencias a esta obra (nueve en total), tal vez colocada en la mente de la escritora como obra primeriza, era ya reconocida como auténtico Drama wagneriano; recordemos su afirmación, hablando de un muy inicial Rienzi, del cual lo diferencia, que "Mucho tiempo tardó en aparecer con su cisne Lohengrin..." (1914), al que bien podríamos sumar este Tannhäuser. En esta línea, ya comentada, recordemos al castizo madrileño amante, justamente de estos últimos dramas mencionados (van como "juntos" en el punto de comentario de estas tan especiales piezas wagnerianas), ya en 1889 (Al pie de la Torre Eiffel), y más adelante, en 1914, vuelven a ir de la mano a la hora de los comentarios:

...tuvieron los señoritos elegantes, rabiando o rezando, que apencar con Lohengrin y después con Tannhäuser. Pusieron a Wagner de pesado y latoso que no había por donde asirle, eso sí: no obstante, quedaron ambas obras en el repertorio: Y no fue esto lo más, sino, que ya empezaron a encontrar dificultades las "Lucías" y "Sonámbulas", "vieux jeux". Sólo al amparo de algún tenor o tiple de primer orden, como Gayarre y la Patti, se sufrieron las "Traviatas" y las "Favoritas". Vinieron entonces a sostener el pabellón de Italia otras óperas modernas: Tosca, Bohemia, Payasos: no importa; los inteligentes ya estaban engolosinados con Wagner (LN, 10/II/1914).

\section{LOS MAESTROS CANTORES DE NUREMBERG (1893).}

Dice J. Paz (2006: 216) que las críticas al estreno en el Teatro Real para con Los Maestros Cantores, "fueron razonablemente hostiles". El caso es que el plan escénico de esta más que madura obra del maestro (ve la luz primera en el Teatro de la Ópera de Munich, un 21 de junio de 1868, con éxito clamoroso y un Luis II extasiado) es de sencilla ejecución y hasta se pueden aprovechar muchas telas de otras obras, ya que un ambiente de villa centroeuropea del siglo XVI compagina con un Rigoletto (acto tercero), un Guillermo Tell o Falstaff, además, casi puede prescindir de la escasa tramoya.

El acto I es en el interior de una iglesia, la de Santa Catalina, fácil por tanto de colocar de no pocas óperas; el acto II es un plaza de un pueblo (Nuremberg), con árbol saúco delante, con otra casa a la derecha de Pogner, con tilo que da su sombra, es el ambiente de la Johannistag/Johannisfest/Johannisnacht. El acto III, escena $1^{\circ}$, es una habitación-taller de Hans Sachs, austero, con un banco de trabajo como utilaje. 
En la escena $2^{\circ}$, un prado preparado para el certamen, al día siguiente, en mañana de San Juan. Giorgio Busato fue el encargado de seleccionar la escenografía, y contamos con material de dibujo del mismo autor para bocetar sus trabajos para Maestros Cantores y una fotografía que bien podría representar el acto II.

Solo recibe una referencia esta obra extraordinaria y poco solicitada por Pardo Bazán, aunque bien diferenciada de las restantes: "Los maestros cantores", esa deliciosa facecia genial, esa sátira contra el frío clasicismo" (LN. 10/II/1914). Pero puede haber algo más de fondo en la creación literaria a través del personaje de Eva, ya nombre simbólico de por sí, que esta vez es la que descubre "el sublime y preciado fruto del árbol de la vida" ${ }^{34}$, en la voz de Hans Sachs, el otro fiel de la amable (y dura) balanza de esta especial "pareja".

En Dulce Dueño (1911) se dan cita una serie de elementos que nos hacen recordar a algunas situaciones y personajes que también se desarrollan en Los Maestros Cantores. Empezando por el nombre de la principal amiga de Eva, Lena (Magdalena, aunque también es simbólico David, su poeta y enamorado pretendiente) que es sonoro con el de Lina (Catalina Mascareñas, la protagonista de la novela). El personaje de Farnesio, persona mayor, tutor y amigo íntimo de la viuda Catalina, a quien la misma deja toda la herencia a su sobrina Lena, es un ilustre señor que siempre se ha sentido enamorado en secreto de la señora Catalina ("Tía Catalina"), siempre atenta a la espiritualidad, al arte,

[Farnesio] es el útil, el imprescindible (...). La buena posición de doña Catalina atrae pretendientes; pero Farnesio, hábilmente, los aleja, los desconceptúa... (...). Farnesio no quiere saltar el peldaño, al contrario, desea por hidalguía, por abnegación, seguir siendo el inferior, el dependiente, el que en la sombra vela por una dama y una estirpe. La idea del matrimonio, que no hubiese sido antipática a la pasiva doña Catalina [su tía y ya viuda], él la rechaza reiteradamente, definitivamente; no rebajará a la mujer amada (...) no la hará avergonzarse ante su hijo, no suscitará la menor complicación para el porvenir. El alter de la honra y del decoro, pide una víctima: la víctima seré yo. (p. 146-147).

Es un tema universal, pero selecto el de la "renuncia por amor", el no tratar de impedir que, enamorado uno, reconozca que su amada quiere realmente a otro, aunque siempre haya una más que una buena relación entre amante en las sombras y amada, ésta, de años normalmente más jóvenes, y aquél, mayor y experto, ya experimentado en amores lejanos o enviudados. Se sacrifica la felicidad de la amada por la renuncia del amado no correspondido. Ya lo conocíamos en el tema de Wolfram von Esenbach, en Tannhäuser, atraído perpetuamente por Elisabeth, aunque ésta sueñe y hasta pueda redimir espiritualmente a su ambiguo y amado Heinrich.

34 En acto III, escena segunda. 
Eva y Elisabeth saben del amor puro que los extraños amantes sienten por ellas desde el eterno segundo plano, a los que la amada los relega amablemente, aunque realmente los salven...Se relata, en boca de Hans Sachs (Acto III, escena $\left.4^{a}\right)^{35}$, otros paralelos en wagneriano, el del Rey Marke del Tristán, amén del sublime pero muy secundario y comentado Wolfram.

Con Hans Sachs, Wagner, quiere elevar el heroico papel de un personaje tan especial y solo aparentemente secundario, pues no forma parte de la pareja principal de Eva (nombre propio de sentido bíblico, prístino) y Walther, y así, desde el principio se va entretejiendo la verdad de este ennoblecido sentimiento:

1. En la cuarta escena del segundo acto, Eva está en la calle, se acerca al taller del zapatero, que está en la puerta de la casa: Eva se expresa claramente:"...Dios sabe a quién tendréis / ahora en el corazón / donde he creído estar / durante tantos años (...)". Y: "Y entonces pensé / que me acogeríais / en vuestra casa como mujer / y como hija".

2. En el acto tercero, primera escena, el Wahn!, Wahn! Überall Wahn! de Sachs, auténtico expositor de intenciones de un hombre cabal, profundo y de visión transcendente de la vida, ya adelanta el noble posicionamiento del zapatero ante el amor humano, sublime sí, aunque de vana ilusión, perecedera en tanto que "ilusión", un Hamlet wagneriano: “illusión! ¡llusión! / ¡Por doquier la loca ilusión! / Adonde quiera que mire, / en la crónica de la ciudad / y en la del mundo / siempre he de preguntarme / por qué las gentes / se atormentan y disputan / hasta incluso verter la sangre / con estúpido y absurdo encono". Más adelante, "No dejo que en mí / disminuya la esperanza, / y así nada puede disiparla".

3. Cuando Sachs descalza a Eva, la clienta de su zapatos, el maduro cantor expresa lo que le va diciendo su corazón: "He pensado / cómo poner alguna vez / fin a este trabajar: / a lo mejor, todavía / me presento al concurso, / y entonces ganaría / algo como poeta...". Eva sabe que aceptaría un matrimonio con Hans como mal menor, si ésta gana el concurso de cantores, antes de su soltería, pero el hombre maduro y enamorado que guarda en su corazón el sueño de amor por la joven, controla y obedece a su nobleza, que le exige el sacrificio de no dejar que la joven pierda la alegría de su vida casándose con él, aunque a éste le duela en su ser más profundo. Eva antes que él mismo: es lo que tienen los personajes wagnerianos.

Para el Teatro Real, se recordarán, entre otras, las perfomances de Los Maestros Cantores en la temporada de 1912-1913 y las extras del mismo año 1912, ya en marzo.

\footnotetext{
35 Dice Hans Sachs a Eva: "Niña mía, / conozco una historia triste, / la de Tristán e Isolda: / Hans Sachs fue inteligente, / y no ha querido nada / de la dicha del rey Marke... / Ya era tiempo de que / hallásemos al que te conviene, / aunque al final habría / sucedido lo mismo“, (acto III, escena cuarta).
} 


\section{5. "Y SE ESTRENÓ LA WALKYRIA" (1899).}

La admiración por Wagner es más que incesante en E. Pardo Bazán. Die Walküre es estrenada en el Teatro Real un 19 de enero de 1899 (temporada 49) (36 $^{36}$ y la expectación se palpaba en los ambientes y medios de información de Madrid y prensa de todo el país. El último trabajo de Giorgio Busato para su Teatro debía encumbrar su ciclo de escenógrafo y artista consagrado, y se dispuso para ello con La Walkyria, obra de gran aparato escénico (artificios que se reflejan en panoplias para explicar los mismos, su maquinaria), tecnología punta del momento, decorados especiales, vestuario no muy ortodoxo para el momento, etc. Pardo Bazán también se empleó a fondo para tratar como era debido una obra cuyo "estreno venía revestido de carácter de gran acontecimiento" (Paz, 2006: 223), en febrero y marzo ya hay dos referencias directas del estreno:

[Crónica del estreno de La Wakyria en el Real: crítica al público insensible; Wagner como símbolo de europeísmo] Y se estrenó La Walkyria, y no gustó, y salió todo el mundo hablando de jarabe de adormideras (...). Algunos, es cierto, estuvimos como en misa, y no dejamos de halagar deleitosamente el oído y la imaginación con el perfectísimo tercer acto de la segunda parte de la tetralogía; con la maravillosa cabalgada y la divinamente suave y misteriosa encantación del fuego, páginas que ellas solas bastan para diputar a Wagner por incomparable artista (...).

¿Es necesario concentrarse para sentir la hermosura del fuego encantado, el brío marcial y terrible de la gritería walkyriana, las frases de acero de Brunilda, la melodía delicadísima y sugestiva del Canto a la primavera? ¿No bastan los nervios, la imaginación, el oído? Creo que sí (...) La suma belleza artística siempre es directa, fulminante, fuerte y poderosa. Se impone. ¡Y sostener que Wagner adormece! Lo que hace es despabilar. Una audición sentida de La Walkyria consume mucho fluido nervioso. Naturalmente el que se propone no escucharla no gasta un céntimo...(...)

El público español, en general, es enemigo de lo nuevo y de lo extranjero, solo por ser extranjero y nuevo. Nuestra naturaleza nos inclina al oficio de aduaneros intelectuales. Nuestro orgullo vano nos incita a desdeñar lo que no producimos. al mismo tiempo que no prestamos gran atención a lo que producimos, como si fuese tan fácil hinchar un perro. En la segunda representación de La Walkyria no faltó quien remedase, aprovechándose de la semiobscuridad en que queda la sala, gruñidos de animales y ronquidos irónicos. He aquí el medio de la cultura dominante; por esta medida la despachamos...Arriba y abajo se parecen más de lo que a primera vista creerá cualquiera. ¡Imitar el cerdo en La Walkyria!

Y así y todo es de esperar que Wagner triunfará en el "regio coliseo" como ha triunfado ya en los conciertos (...) Para entonces ya estaremos todos archiregenerados, nos habrán vuelto del revés, y formaremos parte de Europa. Parsifal será para nosotros un símbolo. Ya se sabe que Parsifal es el destinado

\footnotetext{
36 Primicia en España, ya que el Liceu barcelonés hace lo propio un 25 de enero del mismo año 1899. Doña Emilia hace un guiño a este adelanto de los madrileños sobre los "wagnerianos" catalanes, "Por fin este año los públicos de Madrid y de Barcelona han podido ver realizados sus deseos, y justo es que dediquemos un aplauso a los señores Paris y Vehils, que como empresarios del Real y de nuestro Liceo respectivamente, han dado a conocer tan maravillosa partitura” (LIA, 6/II/1899).
} 
a rescatar los pecados y los yerros de Amfortas, el que disipa las sombras y las tinieblas del mal, el que restaña la sangre de la eterna herida. (LIA, 6/II/1899).

¡Bayreuth en Madrid! Los que recuerden una de mis últimas crónicas y la acogida que el público dispensó a La Walkyria, una de las partes más bellas de la tetralogía, no dejarán de notar evidente contradicción entre este hecho y la frialdad y hasta hostilidad que Wagner encontró en nuestras esferas de cultura social más elevada. (LIA, 6/III/1899).

Sí, han leído bien, La Walkyria es, definitivamente la obra-guía de un pueblo a regenerar (en todas sus capas sociales por cierto), de una Europa a blandir contra la insensibilidad y falta de perspectiva de los nuevos horizontes que se avenían para mayor altura de la belleza y de su "Arte del Porvenir", contra la bestialidad que sobresale desde la "semiobscuridad", en conclusión contra todo lo que signifiquen "aduaneros intelectuales" en este país en sincero retroceso y necesario regeneracionismo (el desastre de Cuba, demasiado cercano). Casi nada.

Para el acto $1^{\circ}$ se tomaron las referencias escenográficas de $\mathrm{H}$. Breling (1882, estreno en Munich, 26/VI/1870) y de Soler Rovirosa (1899). Escogiendo Busato y Amalio una escenografía muy tradicional sobre los modelos del estreno: cabaña de Hunding, interior con fresno, cuyas veteranas ramas atravesaban partes del techo (fuera, violenta tempestad), en cuyo tronco está insertada la espada Nothung. El acto ${ } I^{\circ}$ es un paisaje montañoso con desfiladero entre dos rocas que sobresalen, con una cueva-gruta en primer plano. El $3^{\circ}$ acto es la cima de un peñasco de ese paisaje general (escena $1^{\mathrm{a}}$ ), pero es en los efectos especiales donde estaban las dificultades, pues desea que las walkyrias literalmente cabalguen volando por los cielos, en definitiva, que se construye una rampa por la que suben caballos de verdad con sus guerreras mensajeras, así se representaba en un boceto de G. Busato y Amalio Fernández.

La base informativa de nuestra escritora va a ser la historia de la literatura germánica (Cantar de los Nibelungos), la mitología germánico-escandinava y ese libro ya remitido de Rodrigo Soriano, La Walkyria (1898), que no sólo versa sobre dicha obra (clave para la comprensión de todo el Anillo del Nibelungo) sino alrededor de prácticamente toda la Tetralogía (cita de LIA 6/II1899, igualmente es referida al lado del Lohengrin y Tannhäuser), amenizado con notas de mitología, grabados e ilustraciones de cierto valor, extraídos directamente de las fuentes del Bayreuth finisecular. Esta obra angular de La Wallyria, merecería 11 referencias totales (tercera en insistencia, después del Lohengrin y Parsifal) en sus reseñas y citas de la obra periodística y ninguna en sus obras literarias y de viajes, aunque es relacionada cuando se desarrolla el tema de Mitología y leyendas germánicas (12 ítems) y personajes wagnerianos (9 referencias). 


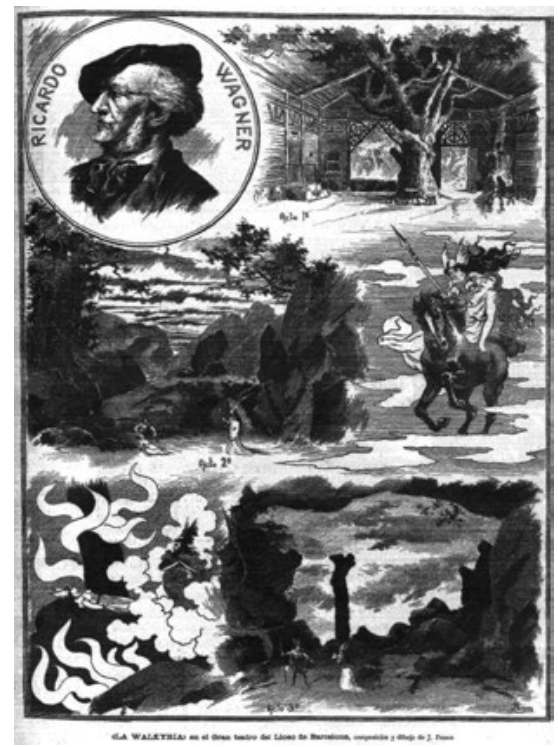

Gráfico relativo al estreno del La Walkyria en Barcelona, publicado junto al artículo de

E. Pardo Bazán (LIA, 6/II/1899, p. 91).

Aunque no lo cuestiona, le sigue llamando la atención a esta asidua del "paraíso", la reacción de las personas ante la magna obra germánica, y las versiones adaptadas a la lengua italiana o al español...entre otros temas, siempre insertos en la obra general del Anillo,

[Comparando ópera y zarzuela y disertando sobre la conveniencia o no de traducir el libreto al español para determinadas obras...] El año pasado se cantó en el Real La Walkyria en español, y recuerdo que, a pesar de la sublimidad de la partitura, el público sentía ganas de reír cuando alguna frase, por ejemplo aquella de "Prepara el hidromiel" se destacaba sobre la música y resonaba secamente (...) Las zarzuelas, es cierto, se han cantado en español siempre, y no han provocado a risa. Quizás sea porque las zarzuelas no tienen las pretensiones de la ópera, ni se exhiben en el Real, ni se asiste a ellas con frac y gardenia a la boutonnière (...) Lo cierto es que las zarzuelas han merecido mejor trato que las óperas. Yo, que no entiendo de música, que estimo siempre el esfuerzo y el trabajo artístico, porque sé cuánto cuesta, cuán arduo es, me guardaría de calificar severamente ni a la recién estrenada Raquel [T. Bretón] ni a ninguna de las óperas españolas que han aparecido con varia fortuna en el teatro Real; me limito, pues, a decir que, habitualmente, los espectadores salen rabiando de los estrenos a que aludo. Cierto que también salían furiosos de la Walkyria y del Barco Fantasma y de Lohengrin la primera vez; cierto que han ido habituándose a algunas obras españolas, por ejemplo Los amantes de Teruel y Garín, oídas ambas ya con tolerancia y aun con gusto y complacencia y admiración (...) No entra en la gente la ópera nacional. (LIA, 29/I/1900).

[Escuchando un concierto de piano (no era precisamente su instrumento favorito...) interpretado por un polaco, improvisando; las Walkyrias como elemento 
heroico musical] A veces, un soplo heroico erizaba la cabellera de lino mal tascado del artista, y una marcha guerrera estridente, se alzaba, retando al universo con sus sonoridades briosas. Clamores de muerto y de sangre parecían estallar en el aire como maldiciones, como si las vírgenes belicosas, las Walkirias nunca saciadas, galopasen allá por entre las nubes (LIA, 8/X/1906).

[Quejas de EPB sobre las pocas representaciones wagnerianas en el Real y su comparativa con las óperas italianas y demás; origen mitológico de la tetralogía] No hemos conseguido sin embargo los aficionados legítimos lo que sería nuestro ideal: la temporada wagneriana, en que nos den seguidas las obras del maestro, empezando por El Barco Fantasma y acabando por Parsifal. Nos han dejado, como suele decirse, a media miel, en lo relativo a la tetralogía. Pocas veces hemos visto alzarse la cortina para escuchar El oro del Rhin y El ocaso de los dioses. Algo más se oyó, Sigfrido y La Walkyria, pero no mucho (...)

La mitología germánica, los primitivos cultos tribales, confusos y grandiosos, los muertos dioses de las espesas selvas y montañas, Wotan, Freya, Thor, los Nibelungos, el período de los héroes, las Valkirias, fueron la tela sobre la cual está bordada la tetralogía. (LIA, 19/I/1914).

[Crítica a los que tildan a Wagner como "rey de la lata"]...aun cuando el wagnerismo se ha desarrollado, se ha impuesto y conquistado a los concurrentes al "paraíso", las localidades altas, que acaban siempre por hacer ley quedan, en la localidades bajas, partidarios de la música italiana, no porque no obliga a fijar tanto la atención como la otra...Y aún existen calvos y canos, con abdomen y nuca roja, algunos señores que recuerdan los "buenos tiempos" del Real, los triunfos de divos y divas (...)

Y los que así se expresan, son los que afectan a entregarse a un sueñecito defensor, apenas aparece la Walkiria, rodeada de fuego, o Sigfredo fatídicamente avisado de su destino por las hijas del Rhin..."Somos de otra raza que los alemanes" protestan. "Para ellos, esto será canela fina. Para nosotros, es demasiado "sabio"...Y si esto han dicho de Lohengrin y de la claridad diáfana del Ocaso de los dioses, ¡qué no dirán, oh cielos de Parsifal!. (LN, 27/XII/1913).

Los otros temas seleccionados ya los hemos observado cuando se trata de la supresión de escenas y falta de delicadeza en la guardarropía-atrezzo (LIA, 20/ III/1899), o meras asociaciones con la Tetralogía (LN, 10/II/1914).

Finalmente, y enlazando con lo ya desarrollado en otro apartado, todo arte, estética, literatura, mitología-iconografía o intelectualidad como producto relacionado con lo alemán, germánico o nórdico en armas (las del momento, las del I a Guerra Mundial) va a ser relacionado, especialmente con el Anillo del NibelungoTetralogía, aunque de lo que trate dicha obra sea un propósito tan elevadamente universal como transcendental. No importa, es germanofilia en vena para los ambientes pro-aliados ${ }^{37}$, mayoritarios por abrumador número en los madriles de la "neutralidad" española. El punto de vista de Doña Emilia para con La Walkyria deberá ser especialmente templado y reconciliador:

\footnotetext{
37 Recuérdese que esa es una, no la única ciertamente, de las principales razones de la desaparición de la Asociación Wagneriana de Madrid en 1915.
} 
[sobre el origen del espíritu germánico, en plena $1{ }^{\mathrm{a}} \mathrm{GM}$ ] Las hijas de Wotan, cabalgando en sus corceles que relinchan al olfatear la sangre, lanzando salvajes gritos de alegría al ver los cadáveres extendidos sobre el campo de batalla, eran las inspiradoras de las tribus belicosas, castas y feroces. (LIA, 19/VII/1915).

[Anti-germanismo después de la $1{ }^{\mathrm{a}} \mathrm{GM}$ y censura sobre la obra wagneriana; apertura a la misma] Privados durante los últimos años de la guerra de oír las óperas de Wagner, ahora parece que va a alzarse el veto, y que nos darán Valkiria, Sigfrido y Lohengrin, por lo menos. (...) siempre sublevaría a un enamorado de la belleza la proscripción del arte, que debiera volar por encima de las luchas y contiendas entre pueblos. El arte es de todos, y aun cuando por eminencia el arte sea patria, y nada más patria que el arte, tiene la virtud de llevar en sí la esencia de la patria, sin exclusivismos ni xenofobias de ningún género. Todo francés de espíritu abierto amará el arte germánico después de la guerra. Reconocerá su valor propio, y no querrá privarse de él, porque ese patrimonio espiritual al cual pueden aspirar todos, hay que defenderlo y conservarlo celosamente. (LN, 20/I/1920).

\section{SIGFRIDO (1901), EL OCASO DE LOS DIOSES (1909) Y EL ORO DEL RHIN (1910). SE COMPLETA LA TETRALOGÍA DEL ANILLO DEL NIBELUNGO.}

Una vez más, se asocia el mundo de la literatura (altomedieval y legendaria) y la mitología germánica con toda la temática del Anillo, así, estas tres obras completan (en orden de estreno casi inverso) la representación íntegra del mismo. Ratifican las partes restantes a La Walkyria, por su importancia, como la obra principal de esta entrega genial y es por ello que merecía trato singular dentro de la obra general: así lo estimó la escritora.

Le dedica Pardo Bazán al tema de los personajes wagnerianos 9 ítems, donde Sigfrido, Wotan, Freya, Thor, Brunilda, Sieglinde y Siegmund son principales, pero las Hijas/Ondinas del Rhin (7 ítems) son una reiteración muy querida en formatos de novela, cuentos y asuntos de mitología germánica en general (lo habíamos dicho junto con las walkyrias, 12 ítems). No es tema baladí, aunque se suele tratar de una manera global todo el ciclo.

En sus libros de viajes, uno en concreto, Por Francia y Alemania (1889), ya nos hace incorporar el Rhin como elemento estético, vivencial:

[Lago Constanza, Baviera] "Era una suerte encontrar tan hermoso tiempo, porque este charco de ondinas, en cuyo seno el Rhin derrama el agua que le sobra, cubre a veces su túnica con un velo de niebla tan espesa, que sólo ayudados de una brújula pueden en el orientarse los marinos (...) Maguncia, la patria de Guttemberg, donde el Rhin corre ancho y majestuoso, me seducía igualmente (Por Francia y Alemania, 1889, pp. 367 y 373 ) 
En su novela Dulce Dueño (1911), hablando Catalina del lago Constanza (como hemos visto, sin duda su experiencia de joven viajera en Centroeuropa ya le había ejercitado su imaginación y admiración por tan especial singladura) ya nos relata,

El Rin, que forma estos lagos entre los cuales Constanza remeda el broche de una clámide, es al menos, un río cuya imagen he visto en mis deseos, un río de leyenda (...). El Rin me atrae, de buen grado pasaría la frontera y recorrería Baviera y Tirol, aunque sospecho que pudieran parecerme exactamente a Suiza (Dulce Dueño, 1911, pp. 232-233).

En La Sirena Negra (1908) el elemento del agua, la sirena, son elementos purificadores, regeneradores para la muerte y salvación del protagonista Gaspar de Montenegro:

Y unas pupilas oscuras, enormes -de asfalto y tinieblas, como las de Rita Quiñones, la pecadora- me miraban desde el hondón del agua. Sí eran pupilas de mujer -porque lo sobrenatural, sentimental, para el varón, es siempre femenino-, al menos la mujer no alzaba del agua ni el torso mórbido ni la grupa redonda, ni blanqueaban sus carnes bajo la linfa, ni debía poseer cabellera rubia como la de las hijas del Rhin (La Sirena Negra, pp. 75-76).

...O comentando a un Héctor Berlioz, muy en la senda del maestro: "Este francés se ha bañado en el Rhin y ha visto a la Loreley de cabellos de oro" (LIA, 29/I/1906), al mismo tiempo que se ensalza el atrevimiento de Wagner por el topoi de la mitologíaleyenda para convertirla en otro producto, ensalzado y mejorado, actual:

Uniendo el pasado con el presente con lazos de oro, Wagner ha logrado quitar a la evocación del ayer esa frialdad arqueológica, ese gris de telaraña, que la apartan de nosotros, y la aíslan de la vida actual. No hay gente más moderna y contemporánea, en cierto respecto, que Tristán e Iseo, el caballero Tannhäuser y el héroe Sigfrido (LIA, 21/XII/1914)

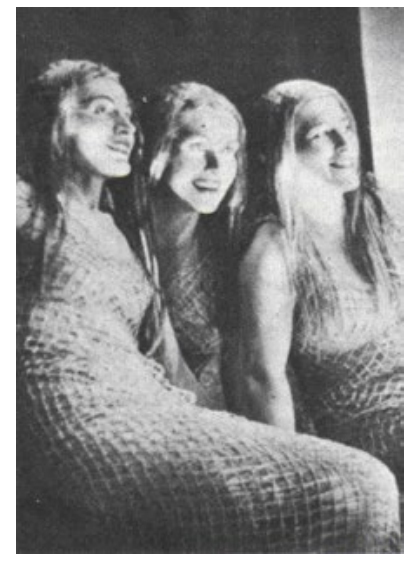

Las tres Hijas del Rhin (Woglinde, Wellgunde y Flosshilde), en Bayreuth de 1951, pero muy à la mode del atrezzo de cominenzos de siglo. 
El hijo de incesto y noble guerrero de walsungos, Sigfrido, ya hemos visto que no sale bien acampado de su comparación con el caballero de Monsalvat en tierras germánicas, Lohengrin (cita en su apartado correspondiente: "Lohengrin no es el héroe niño, como Sigfredo", en Dulce Dueño), y es poco más que referencia al lado de otras obras tetralógicas y del resto, incluida entre las demandadas después del veto a Wagner en pleno ambiente bélico anti-germanista: "...ahora parece que va alzarse el veto, y que nos darán Valkiria, Sigfrido y Lohengrin" (LN, 20///1920), pero es el personaje literario de Sigfrido el que se analiza, y una vez más se asocia con el mundo mítico-literario:

...tradiciones germánicas y escandinavas, tan hábilmente aprovechadas por Ricardo Wagner, el magnífico mito de Sigfrido estriba en eso: en ignorar el miedo. Por ignorarlo, puede forjar la espada Nothung, que se resiste al martillo del cobarde gnomo; por ignorarlo, puede herir en el corazón al dragón Fafner, que custodia el anillo de los Nibelungos (...) Aquiles no sueña, no piensa sino en el honor. (LIA, 13/III/1916).

Para pasmo de algunos, tiene buena aceptación la segunda entrega del Anillo, Siegfried, ahora ésta es emparejada con Parsifal para defender y ensalzar la obra wagneriana sobre el ballet y la coreografía rusa:

A mi ver, ni la poesía ni la música, ni ambas cosas reunidas como en Parsifal o Sigfrido, pueden soportar que se las ponga en parangón, o por debajo de estos bailables, que dejan una impresión mixta de cinematógrafo y acrobatismo, y por momentos, de interesante reconstrucción arqueológica (LIA, 14/VI/1916).

Hablando de la insistencia del número de referencias de estas obras, algo parecido acontece para con el prólogo El Oro del Rhin (2 referencias en la obra total de la autora) y El Ocaso de los dioses (5 ítems). Las representaciones y deseos sobre la Tetralogía ya han recibido por nuestra parte un tratamiento conjunto en citas ya expuestas (v. LIA, 19/I/1914), dichas obras son constantemente relacionadas con las ondinas/hijas del Rhin, y el propio río Rhin como hemos visto, o con el mundo heroico-mitológico (ironía en tono negativo desde los anti-wagnerianos): "El demonio que apenque con Erda, los enanos, Fafner el dragón y toda esa mitología escandinava sin precedentes en nuestra fantasía, sin raíces en nuestras tradiciones!", (LN, 17/I/1910).

El caso es que Sigfrido hace abrir el telón del Real de la corte y villa un 7 de marzo de 1901, a modo de una prueba de fuego de forja y templanza de espada para el escenógrafo manchego Amalio Fernández, ahora en su taller de trabajo sin su maestro Busato. El formato escenográfico de Amalio (aunque hay innegables influencias de Adolphe Appia) lo toma casi literalmente de las representaciones de 
Bayreuth, donde se había estrenado el 16 de agosto de 1876. Se sobreentiende que las técnicas utilizadas para los fuegos celestes y subterráneos (entradas y salidas de Wotan en escena), el amanecer del bosque, su curioso pájaro cantor y traductor, o la aparición de Erda no debieron quedar sin imaginativos ingenios: efectos de luz eléctrica, vapores de agua; "Fafner es movido por cinco hombres" (Muñoz Morillejo lo relata, pero las indicaciones de Bayreuth son explícitas y gráficas) ${ }^{38}$, "la mutación de tercer acto es sorprendente: el vapor de agua ocultaba la escena unos instantes", "las decoraciones de Amalio eran un prodigio de belleza y mecánica teatral. Superpuestas habilísimamente las dos del cuarto (tercer) acto, una ocultando a la otra, facilitaba mucho la tarea de sustituir detalles en un momento de la mutación". La intermisión de las ideas estéticas, más abstractas, de A. Appia hacen mella en Amalio, especialmente en el acto $3^{\circ}$.

Para el Ocaso de los dioses (Götterdämmerung), se reutilizaron las pinturas escenográficas que el director Amalio habría utilizado para Fausto y el Raimundo Lulio de Ricardo Villa (¿el interior de su castillo gótico mallorquín?), o simplemente bosques frondosos de seculares árboles, paisajes rocosos, orillas del Rhin y castillo para los guibichungos, también reutilizaciones de otras partes del Anillo, tal y como le pasará al Oro del Rhin. En todo caso, en este día del estreno de 7 de mayo de 1909, ya había entre el público un sector importante de afectos a la obra de Wagner y se fue notando en lo nutrido de las entradas, siempre de éxito. Allí estaría, en el paraíso o en platea (ipor qué no también, de vez en cuando, en palco o butaca?), nuestra ilustre cronista y contemporeanista, entregada ahora al comentario literariomusical que exige Wagner, y esos telones, decorados y tramoyas, que fueron los que ella debió haber visto, iguales o similares, por lo menos gran parte de los mismos.

Una referencia literaria para el Ocaso; se trata de un relato corto, en cierta medida, semejante al del Disfraz con respecto al Lohengrin. Nuestro cuento es Durante el entreacto (1911) nos describe una escena de dos clases sociales bien diferenciadas, y en la lucha por la supervivencia (y conveniencia) del matrimonio (Ginesa y Miguel) humilde al servicio del señor, éste, marqués ("un fuerte sportman"), se presenta inesperadamente en un entreacto del Ocaso, casi como un dios...

Bajando las escaleras aprisa, saltó en el mismo coche que le había traído, para Ilegar al teatro Real, a tiempo de no perder el último acto del Crepúsculo, la entrada de los dioses en el Walhalla (Durante el entreacto).

El Oro del Rhin. Se presenta el comienzo-prólogo de la Tetralogía, por orden invertida en España y Madrid (algo parecido pasa en Barcelona, su estreno es de 30/

\footnotetext{
38 Cfr. J. Paz, 2006; pp. 240-241. La imagen del anexo, movimiento escénico de Fafner, está reproducida en Revista Wagneriana, vol. II, 1978 (v. bibliografía).
} 
III/1910), siendo que el Oro de la Tetralogía ve sus resplandores áureos y linfáticos en 2 de marzo de 1910. Se nos advierte en la obra de Juan Paz (2006) que "no hay noticia alguna de la decoración que se usó, ni tampoco el menor resto gráfico" $(2006: 263)^{39}$, aunque las indicaciones de R. Wagner para esta obra ${ }^{40}$ son nítidas, nos aferramos a que en la perfomance madrileña, el fondo del Rhin se conseguía (acto I) con gasas en primera línea de la escena, a poder ser sin que se viesen las costuras. Para los actos II (montaña rocosa sobre un fondo donde se observa el Walhalla de las desgracias y deudas) vale un castillo con cierta magnificencia y para el acto $1 \mathrm{II}^{\circ}$ un fondo obscuro a modo de "cueva", el reino de los nibelungos. Para el último acto se repite el del primero. No sería difícil la puesta en escena de este prólogo, aunque conviene resaltar que para conseguir el sentido escenográfico de la obra, conviene no descuidar el apoyo visual ante los abstractos temas del Anillo (trompas), los juegos de luces para visualizar el oro desde el lecho del río, su luz en la escena...y el leivmotiv de Wotan (metal).

Los decorados y trasfondos de esta obra (entendida para los madrileños, al revés de su orden natural...) tuvieron que ser los extraídos de los grabados y láminas de las ediciones finiseculares de Bayreuth, y así, las obras de las escenas para el Oro del Rhin de Ferdinad Leeke (obra para la tetralogía de finales del XIX, principios del XX), Heinrich Nisle (decorados explícitos para el Oro del Rhin), Carl E. Doepler (1876), Theodro Pixis (ilustraciones en el Illustrirte Zeitung, 1869, 1876) y las de Joseph Hoffmann (1876), casi todas cercanas a la fecha del estreno en Bayreuth.

Telones y vestuario, con la inspiración y moda del momento, muy naturalista y neo-romántica, tanto es así que las versiones escenográficas de "la Colina", marcarán la tendencia artística de pintores escenográficos como el propio G. Busato y Amilo Fernández, pero especialmente los de la escuela catalana, entre otros, O. Junyent (su Oro, 1910), F. Soler i Rovirosa, Alarma, M. Vilumara, desde los cuales va a destacar su legado artístico en Mestres Cabanes (1898-1990), testigo recogido desde la tradición más espectacularmente wagneriana.

\footnotetext{
39 Paz 2006: 263.

40 R. Wagner para el segundo cuadro de la obra: "Poco a poco las olas se transforman en espesa bruma, la cual, aclarándose gradualmente en una luz crepuscular, se desvanecen convirtiéndose en una fina neblina. Cuando la neblina, desgajándose, va perdiéndose hacia lo alto, se puede apreciar un lugar espacioso en lo alto de una montaña, iluminado por los primeros rayos matinales del amanecer. El sol ilumina, con resplandor creciente, un burgo majestuoso, que se levanta radiante sobre una cima rocosa, en el fondo de la escena. Entre éste y el primer término hay un hermoso valle, por donde pasa el Rhin. A un lado de la escena, Wotan y Fricka yacen dormidos, uno al lado de otro, sobre un prado lleno de flores”, cfr. J. Mota, “Bosques, animales y puestas de sol en la Tetralogía”, 1978 (v. bibliografía), p. 4.
} 


\section{TRISTÁN E ISOLDA (1911).}

Tal fue el impacto de esta obra en los ambientes de teatros, tertulias, público asistente, cafés y foyer que ya el 31 de marzo del mismo año 1911, se crea en Madrid la Asociación Wagneriana de dicha ciudad, nos lo dice con todo lujo de detalles el generoso trabajo de Paloma Ortiz $(2007)^{41}$. Si esta versión del Tristán, bien pudo con el plantel artístico de Galiardi, Guerrini; Rousselière / Viñas. Walter, Challis, Del Pozo, Oliver, Gino Marinuzzi un 5 de febrero de 1911, una vez más, el serio público de Madrid ya estaba más que conquistado por las huestes del ejército del rey Marke. Otras representaciones y seguramente con este elenco, se dieron este mismo año 1911 (diciembre) y siguiente 1912: 13, 16, 19, 24 y 28 de diciembre; 4, 25, 28 de febrero y 3 de marzo. El éxito fue sin duda arrollador y nuestra consagrada literata pudo haber asistido a placer a este abundante e inusual número de representaciones.

Por contraste, otra cosa fue la puesta en escena, configurada como sencilla por el propio Wagner, direccionada por Amalio Fernández, escenificada desde lo más usual, excepto el tratamiento de debía recibir el barco del primer acto (nave de Tristán, Iseo y la tripulación) y el resultado fue un amaño de La Africana (modelo de Cambon y J. Thierry, Ópera de París, 1865, con interpretación literal de G. Busato), pero sin mecanismos basculantes de alta y baja mar. El jardín nocturno del segundo acto se podría haber rescatado de un Romeo y Julieta en versión escenográfica (1873) de Busato: no lo sabemos. Las soluciones escénicas de Max Brukner (Munich, 1865, su estreno) fueron también asimiladas, y hasta "mejoradas", por Soler Rovirosa (ya había aireado sus velas el Tristán en Barcelona en 8/XI/1899) y posteriormente por el genial Mestres Cabanes, pero no circularon por las bambalinas del escenario del Real. En el mismo teatro, seguiremos viendo la misma escenografía en el transcurrir de los años y para ejemplo, una fotografía del acto primero en la temporada de 1924.

Ocupa esta "ópera atlántica" de literatura céltico-bretona, un lugar no muy destacado como a primera vista pudiera parecer en la pluma de Pardo Bazán, aunque sí obra admirada, y son algo tardíos los comentarios sobre esta pieza clave del devenir wagneriano, coincidiendo éstos con el estreno y las posteriores representaciones de nuestra obra en el teatro madrileño. Son cinco las referencias que cotejamos relativas al Tristán, todas ellas de la prensa de La Ilustración Artística (1914-1916) y La Nación (1910, 1912, 1910), ninguna directamente de su obra novelesca.

\footnotetext{
41 Las palabras son de José Borrell: “A raíz del gran éxito que obtuvo el “Tristán” en Madrid, se pensó entre un corrillo de los más destacados wagneristas de entonces, en la constitución de una Sociedad similar a las muchas que desde ya largo tiempo funcionaban en numerosas ciudades extranjeras", Ortiz de Urbina 2007: 17. Son el mismo J. Borrell, con Manuel de Cendra y el prestigioso director musical de la Orquesta Sinfónica de Madrid, Enrique Fernández Arbós (muy conocido en Coruña y en el mismo Teatro Principal de la ciudad, ahora llamado "Rosalía Castro" desde 1909...), los primeros en iniciar la andadura asociacionista de defensa y difusión de la obra wagneriana en la capital de España, aun cuando Barcelona ya la iniciase en 1901.
} 
Siendo una de sus fuentes de referencia e inspiración, la histórico-literaria y medieval, Doña Emilia se siente segura a la hora de hacer un primer balance de la misma, aunque no pasa de meras anotaciones "al margen" (hablando del origen legendario de dieron lugar a la mayoría de los dramas wagnerianos): "Otras fábulas del ciclo bretón crearon a Tristán e Iseo" (LN, 19/I/1914).

Se despacha a gusto en un importante artículo sobre los libros de caballerías, incluyendo "los cuentos de la materia de Bretaña", insertándolo en el ciclo del Grial y de los Caballeros de la Tabla Redonda, pero la leyenda de Tristán contiene algo especial, es diferente para la autora:

El libro de caballerías que más habla al sentimiento es la historia de Tristán de Leonís, que ha dado a Wagner tan sublime tema para una de sus mejores creaciones (...). Pero ello es que beben el simbólico filtro, y su amor se desencadena (...) $\mathrm{Y}$ aquí surge el enredo de las dos Iseos, que complica lo que Wagner, con muy buen acuerdo, simplificó (...) Tristán quiere ver a su amada, y envía a Bretaña un mensajero que la ha de traer. Quiere exhalar el último aliento en sus brazos. Esta es la escena en que derrochó Wagner su inspiración (...)

...y recordando la letra del dúo del Tristán e Iseo, deciden suicidarse, y así lo hacen, en lírico transporte (LIA, 13/III/1916).

La literatura y el Tristán e Iseo como antropología literaria. Con algún esfuerzo erudito se puede observar, leyendo la obra La madre Naturaleza (1887), cierta influencia del amor sublime, al tiempo que tremendamente humano y atrayente (luz/sombra, noche/día, condena/libertad, realidad palpable/mundo mágico) en exhuberante (¿y redentora?) naturaleza. Entre los capítulos XIX ${ }^{42}$ y XXI de la misma, observaremos los comportamientos amorosos, paisajísticos (dominio de la técnica paisajística como pocos, rozando ya el impresionismo...), ascendientes, dinámicos diríamos, de Perucho y Manuela, y hasta ésta pide de beber a María "la Sabia" entre bruja y vaquera (¿recordando a Brangana?); se siente en toda la acción del caminar y ascender, la atracción de yin/yan a escala muy real y gradualmente ardiente, en el dominio de un liebestod, del impulso inevitable, al mismo tiempo que elevado:

La intensidad del calor arrancaba a los pinos todos sus olores de resina, a las plantas sus balsámicas exhalaciones; y entre el sol que le requemaba la sangre y el vaho que se elevaba de la ebullición de la tierra, y la leche que le aletargaba el cerebro, Manuela sentía como un comienzo de embriaguez, el estado inicial de la borrachera alcohólica, que pareciendo excitación no es en realidad sino sopor; el estado en que las manos resbalan sobre el objeto que quieren asir, en que los movimientos del cuerpo no obedecen a la voluntad, en que nos sentamos sin pesar sobre la silla y nos levantamos y andamos sin estribar en el suelo, porque el sentimiento de la gravedad se ha amortiguado mucho, y nuestras percepciones son vagas y turbias, y parece que ha desaparecido la resistencia de los medios, la

42 Edición de Ignacio Javier López, ed. Cátedra (v. bibliografía). Capítulos XIX-XXI, pp. 269-300. 
densidad de la materia, la dureza de las esquinas y ángulos, y que los objetos en derredor se han vuelto fluidos, y nuestro cuerpo también, y más que nada nuestro pensamiento.

No es desagradable el estado, al contrario, y la plétora de vida que produce se revelaba en el rostro de Manuela: sus ojos brillaban y su boca sonreía sin interrupción. La niña no preguntaba ya cosa alguna a su compañero: andaba, andaba tan ligera como se anda en sueños, sin sombra de cansancio, aunque apoyándose en Perucho y arrimándose a su cuerpo con instintiva ternura. (p. 278)

[Se aproxima el momento sublime, ascendiendo una cima después de esfuerzos de la pareja, entre embelesados y tiernos, de comer miel rubia] Las correctas líneas del rostro de Perucho se crisparon. Las raras veces que tal sucedía, palidecían sus mejillas un poco, dilatábansele las fosas nasales, se oscurecían y centelleaban sus ojos de zafiro, poníase más guapo que nunca, y era notable su parecido con las estampas de la Biblia que representan al ángel exterminador o a los vengadores arcángeles que se hospedaron en casa de Lot el patriarca. Manuela lo contemplaba con placer, a hurtadillas; y de pronto, pasándole suavemente una mano por detrás de la cabeza y atrayéndolo a sí, murmuró:

-Tú me gustas más, queridiño.

-A ver, dilo otra vez.

-Te lo daré por escrito. -Hizo ademán de escribir en el suelo con el dedo, y deletreó: Me-gus-tas-más.

-Manola, vidiña... A mí, ¿me quieres más a mí?

-Más, más.

- ¿Te casarás conmigo?

-Contigo. (p. 288)

[Llegando a la cima del Castro, momento culmen con altura, paisaje, calma y mar a lo lejos] Subió lentamente la pareja, no apremiada ya por la angustia de hallarse cerca de sitio habitado que desde por la mañana impulsaba a Perucho a desviarse del caserón. Iban los dos montañeses radiantes de alegría, con el desahogo de la confesión y las promesas anteriores. Parecíales que sin más que trocar aquellas cuatro frases, se les había quitado de delante un estorbo grandísimo, y ensanchándoseles el corazón, y arreglado todo el porvenir a gusto y voluntad suya. En especial el galán no cabía en sí de gozo y orgullo, y sostenía a Manuela y la empujaba por la cintura con la tierna autoridad del que cuida y atiende a una cosa absolutamente propia (...). La soledad era absoluta en aquel lugar elevado y casi inaccesible; el cielo parecía a la vez muy alto y muy próximo, y como nada limitaba la vista, horizonte inmenso lo rodeaba por todas partes, resultando el firmamento verdadera bóveda de azul infinito y profundo, que encerraba a manera de fanal el inmenso anfiteatro. Las lejanías, más bajas que el Castro, se perdían gradualmente en tales tintas rosadas y cenicientas, que formaban la ilusión de un lago, o del mar, cuya extensión se divisase lejos, muy lejos. (p. 292/294).

[La belleza y sublimidad del amor juvenil, el juego de los elementos de la naturaleza: el roble, la encina, el viento, el sol, finalmente el amor humano] Si hermoso era a la vista el pelo de Perucho, no menos dulce al tacto. ¡Con qué elástica suavidad se enroscaban de suyo los bucles alrededor del dedo! ¡Cómo se deshacían y partían cada uno en innumerables anillos, ligeros y gallardos, y cómo volvían luego a unirse en grueso y pesado tirabuzón, el bucle estatuario, la cifra de la gracia espiral! ¡Con qué indisciplina encantadora se esparcían por la frente o se agrupaban en la cima de la cabeza, haciéndola semejante a las testas marmóreas de 
los dioses griegos! Claro está que Manuela no se daba cuenta del carácter clásico de las perfecciones de su amigo, mas no por eso le gustaba menos juguetear con la rizada melena. (...) De vez en cuando, a un leve estremecimiento del follaje charolado del roble, a una caricia más viva, más nerviosa y eléctrica de los dedos de Manuela, Pedro entreabría los párpados, y su mirada clara y azul se cruzaba con la de aquellas pupilas negras, quebradas y enlanguidecidas a la sazón, que lo devoraban. Dos o tres veces retrocedió el montañés, -sintiendo en la conciencia una especie de punzada, un misterioso aviso, que al cabo, no en balde tenía cuatro o seis años más que su compañera, y algo que en rigor podía llamarse conocimiento-; y otras tantas la niña volvió a acercársele, confiada y arrulladora, redoblando los halagos a los suaves rizos y a las redondas mejillas, donde no apuntaba aún ni sombra de barba. Al fin, sin saber cómo, sin estudio, sin premeditación, tan impensadamente como se encuentran las mariposas en la atmósfera primaveral, los rostros se unieron y los labios se juntaron con débil suspiro, mezclándose en los dos alientos el aroma fragante de las frambuesas y fresillas, y residuos del sabor delicioso del panal de miel. (p. 298-300).

Efectivamente, "beben el simbólico filtro, y su amor se desencadena" (LIA, 13/III/1916). Lo veo así, pero aún se puede ver de otras maneras ${ }^{43}$.

\section{PARSIFAL (1914). "DOS CLASES DE MÚSICA ME INTERESAN ESPECIALMENTE: LA RELIGIOSA Y LA POPULAR".}

Primer día del año de 1914. La viuda y Señora de Banga asiste a este "sacro" estreno $^{44}$, justo al acabar el luto por la muerte $(12 / \mathrm{XI} / 1912)$ de su esposo José Quiroga; en ese largo lapsus de más de un año, escucha las óperas del Real por teléfono, y sabemos además que el conflicto de la Gran Guerra estalla con todo su estertor, al lado de la admiración por Wagner; sino ahora, se va a resentir este episodio a corto plazo en los ambientes intelectuales y políticos del momento, pero en esta circunstancia, Parsifal parece que lo hace olvidar todo...

\footnotetext{
43 Hay un curioso artículo de Thomas R. Franz donde se interpreta el idilio y ascensión geográfica de Perucho (Gabriel) y Manuela al Castro Pequeño como una atracción erótico-amorosa ineludible: "Algo invisible les incita a Perucho y Manuela subir a los Castros. Al alcanzar el cenit del Castro Pequeño, sienten el impulso de subir al Mayor también. En cierto sentido la segunda subida reproduce en forma visual la última subida al clímax que experimentamos al escuchar el liebestod del Tristan und Isolde de Wagner. Pero es más, por medio de la subida física Pardo Bazán coloca a sus personajes metafóricamente encima del Sinaí (el Olimpo judaico-cristiano), donde pueden comunicarse con Dios. Esta comunicación con el Dios de la naturaleza es absolutamente necesaria si la novelista va a plantear su mensaje más subversivo: la sugerencia de que el incesto - y tal vez también ciertos otros actos proscritos por la sociedad y las religiones- es tan natural y sancionable como la misma naturaleza, obra pura del Creador", p.35 de La Madre Naturaleza y Paz en la guerra: el intertexto perdido, de Th. R. Franz (1999) in Cuadernos de la Cátedra Miguel de Unamuno, no 34, pp. 29-40.

44 En Acosta, Eva (2007), Emilia Pardo Bazán. La luz... in p. 528: "Una de sus primeras salidas [de EPB] sociales será al Teatro Real, donde se representa una ópera de su adorado Wagner, Parsifal. Doña Emilia asiste incluso a los ensayos".
} 
Es la apoteosis final, la verdadera pasión de Emilia Pardo Bazán por la obra de Richard Wagner que va a ser, sin lugar a dudas, el Parsifal, estrenado con toda clase de expectativas en Madrid, el 1 de enero de 1914 (antes lo hace Barcelona aprovechando la noche de disfunción horaria respecto a Alemania, y así representándose el 31 de diciembre a las once de la noche, año aún 1913), un auténtico festival escénico sacro (Bühnenweihfestspiel) para el cual nuestra autora, consideramos, ya estaba preparada desde hacía ya años (se había leído ensayos sobre el tema desde prácticamente el día del estreno en Bayreuth, el 26/VII/1882), quizás desde aquellos tiempos de no tan joven periodista para El Imparcial, en su tan místico como sonado viaje a Roma, donde queda extasiada al contemplar y ejercer la oración ante el Santo Padre (Mi Romería, 1888) ${ }^{45}$, un precedente y experiencia que ella expresa de una manera extraordinariamente bella y que no siempre ha sido bien comprendida y valorada por los estudiosos pardobazanianos.

Los calificativos para esta final obra wagneriana son extraordinarios respecto a todas las obras musicales conocidas por la escritora afincada en Madrid: "Obra sublime" (enero 1914), "esta su obra maestra y maravillosa" (ídem), "lo más elevado y hermoso del catolicismo" (ídem), "una emoción completamente religiosa" (ídem), "la página musical [las dos Consagraciones] más enorme de cuantas existen, hay que proclamarlo" (ídem), "el más sublime de sus dramas musicales" (LN, 17/I/1910), etc...

El estreno quiere ser el culmen del frenesí wagneriano, para la cual, el público madrileño está en este momento más que preparado ${ }^{46}$, y la repercusión social en

\footnotetext{
45 Son sublimes los fragmentos que podemos extraer se su especialísimo viaje a Roma...después de oír el Tu es Petrus con voces angelicales... "Las voces de lo alto proseguían; un rayo de sol, como de esos que en los cuadros bíblicos caen sobre la frente de Moisés o de Josué, envolvía la exangüe cabeza del Papa y arrancaba el fino destello de la perla oriental de sus canas (...). León XIII alzó sus manos, y en ellas vimos un punto blanquísimo, la hostia. Sólo entonces me di cuenta de lo que me pasaba. Estaba en pie, inmóvil, sin respirar, corriéndome dois hilos de lágrimas por las mejillas. Lloraba en silencio, con una felicidad interior tan grande y verdadera, que creía no estar en el mundo (...) involuntariamente levantaba los ojos a la cúpula, al torrente de luz que caía de ella. No me importa que esta impresión tan real y tan profunda sea o no creída; ignoro si hago bien o mal en narrarla, y sobre todo en analizarla, pues acaso destapar el pomo se evapora la preciosa esencia” (Mi Romería, El fantasma blanco, 1888; edic. 2006, p. 77, v. bibliografía). ¿Es o no una primera experiencia, cual neófita, para un Drama Sagrado, o lo pretende, el Parsifal? Para ustedes la contestación, aunque no va a ser la única ni la última vez en que nuestra autora se estremezca ante la música sagrada, en una iglesia, ante un órgano, un coro... (LIA, 2/X/1899; 25/XII/1899), especialmente cuando se confiesa: “dos clases de música me interesan especialmente: la religiosa y la popular" para después pasar a hablar expresamente de Wagner (LIA, 8/X/1906).
}

\footnotetext{
46 Así lo constata muy detalladamente en el trabajadísimo artículo de LIA (19/I/1914) sobre el Parsifal del estreno: "Hay que notar, entre los rasgos plausibles del público de Madrid, el haber oído Parsifal con devoción, silencio y religiosidad artística. No se ha charlado en los palcos, ni nadie ha tosido, ni se ha entrado en las butacas y metido bulla estando el telón levantado, ni se ha distraído la atención un momento en tantas horas. Algunos espectadores se convirtieron en "gusanos de luz", la Infanta Isabel, que leía no sé si la partitura o el libreto con la correspondiente luz eléctrica. Durante las dos Consagraciones -la página musical más enorme de cuantas existen, hay que proclamarlo- se oiría el vuelo de una mosca, tal era el silencio y la suspensión de los espíritus".
} 
la prensa del momento (El País, El Liberal, La Esfera, El Imparcial, La Época, Blanco y Negro, $A B C$, Heraldo de Madrid, etc.) es abrumadora. No pudieron ser menos las crónicas de la escritora gallega en La Ilustración Artística y La Nación, fuentes principales de nuestra información.

El reparto del estreno, obra completa y sin recortes, fue el de C. Rousselière como Parsifal, M. Verdaguer (Tuturiel), Gandio Mansueto (Gurnemanz), Alice Guszalewicz (Kundry), Viglione-Borghese (Amfortas) y Torres de Luna (Klingsor), así como el amplio plantel de caballeros, escuderos y muchachas-flor. Esta perfomance fue, según el gusto de la época, muy políglota, y así cantaron en sus respectivos idiomas: francés (Rousselière), la Gusalewicz en alemán, y el resto de cantantes y obra, en italiano. Falta mucho para "desitalianización" de la ópera alemana.

La orquesta, bajo la batuta de José Lassalle contaba con 110 músicos y 150 formantes del coro. El horario se dividió en dos partes: el acto primero por la tarde y los otros dos, después de cenar, para acabar avanzada la media noche. Se comenzó a las 16:45 y terminó a media noche ${ }^{47}$ (por primera vez, la escritora relata horario y actos del estreno, con todo lujo de detalles: una auténtica crónica pormenorizada, ¡hasta asiste a los ensayos!). Se tuvieron en cuenta todas las mejoras para vestuario, figurines, accesorios, maquinas, campanas y complejos eléctricos. La fiesta sacra estaba en marcha.

La dirección artística de las magias decorativas que se plasman en los telones de ambientación de esta singular obra de redención cristiana, corrió a cargo de Amalio Fernández, y fue ingente el trabajo que le correspondió ejercer, pues poseemos los escritos e ideas generales, así como los bocetos que se prodigó en mostrar ${ }^{48}$ y publicar.

El primer acto ya son tres telones diferenciados: bosque, templo del Santo Grial y un paisaje en movimiento escénico que corre de izquierda a derecha del espectador, "con un desarrollo de 110 metros en tres planos, constituyendo un panorama en

\footnotetext{
47 En LIA 19/I/1914, leemos, “La función empezó, el día del estreno, a las cinco menos cuarto de la tarde: el primer acto duró hora y tres cuartos, sin que el público diese señal alguna de fatiga [se podía cenar en el entreacto en el foyer del teatro: el Ideal Room]. Al terminar, se hizo una ovación, no tanto a los intérpretes, como a la obra sublime. El acto segundo comenzó a cosa de las diez, y parece que no agradó lo mismo que el primero (...) en parte, porque habiendo asistido al ensayo, he visto la indignación del director de orquesta, al notar las desafinaciones y salidas de tono del coro de las mujeres-flor. Doble lástima, porque este trozo es una de las cosas más deliciosas, más caprichosas de la partitura”. Sabemos que a Pardo Bazán no le agradó demasiado la excesiva extensión de Parsifal al contabilizar ésta, más de seis hora de representación, como vemos sus comentarios en este apartado sobre el Parsifal.

48 Los extractos más extensos que poseemos son los que publica Juan Paz Canalejo (2006), del original de Amalio Fernández en La Ilustración Española y Americana, 22 de diciembre 1913 en un número extraordinario dedicado al estreno y obra del Parsifal, así como noticias del mismo que nos da Paloma Ortiz (2007) de su obra referenciada. Amalio Fernández publica en dicho número, nueve escenografías realizadas ex professo para esta obra tan especial como esperada.
} 
marcha" (de la llustración Americana no de 1913). Los personajes que se encuentran en escena simulan caminar hacia el sitio que se desarrolla la acción en el segundo cuadro" (Ortiz, 2007: 123). El segundo cuadro lo componen la torre de Klíngsor, el jardín encantado y un paisaje desértico. El tercer acto contiene artilugios de movimientos escénicos (ahora de derecha a izquierda, sobre 105 metros), también con tres planos distintos, "Ios personajes figuran aquí avanzar hacia el templo del Santo Grial. Nueve decoraciones por tanto". La buena dirección artístico-escénica de Luis París hará que los difíciles movimientos escénicos sean llevados con coordinación cronometrada, instalando cuatro teléfonos que se intercomunican, regulando y haciendo los movimientos simultáneos en todos los sitios y momentos que convengan.

No faltaron los detalles de la luz y el vestuario: la orquesta interpreta la partitura bajo "una tenue luz azulada", en "una suave oscuridad" (Paz: 124), y respecto al vestuario, los caballeros griálicos vistieron "armadura con escamas plateadas, escudo de plata, como el casco y la cimera, y capa blanca, con una paloma heráldica bordada en la capa", se quiso imitar la uniformología de los caballeros del Temple, sin duda. La relación caballeros templarios-caballeros del Santo Grial, era una asociación que le agradaba sobremanera a Pardo Bazán, como veremos.

Los remites a la obra parsifaliana-griálica en la obra que cotejamos son de 11, al lado de la referencia al Grial en Dulce Dueño (1911), ya citada, y otra de La Quimera (1905) ${ }^{49}$ donde incluso se vincula la redención personal de Silvio Lago con Wagner. No es poco, 12 ítems que por la relación un ítem-cita de obra, superarían al del Lohengrin aunque éste posea "más ítems" en la obra general de la autora. Por ejemplo, las referencias a la obra (con el personaje serían algunas más) Parsifal sólo en LIA, 19/I/1914, ¡suman 14 en total! pero lo contamos como un solo ítem. El cómputo máximo de citas en toda la obra literaria, sería sin duda superior para este Drama Sagrado, favorito de Pardo Bazán, sin duda, aunque con algunas quejas, como podrán observar.

Los temas con que se relaciona a Parsifal desde la perspectiva de la literata son varios, algunos de ellos ya conocidos (la mística, el mundo de la literatura medieval, el ciclo artúrico-Grial, las reliquias y remembranzas de todo surco dejado por el mito griálico) para los que vayan siguiendo el devenir de lo que aquí desarrollamos respecto a las otras obras wagnerianas. Podríamos convenir que estos son los temas principales con que se vincula el Drama musical de Parsifal:

\footnotetext{
49 En página 490 de la edición que manejamos: “...Yo no habré visto en balde correr el líquido sacrosanto que llenó el Grial; y no habré contemplado el misterio de la Sangre...Y además, hace tiempo que mi consciencia trabaja, que el remordimiento de males que causé me lleva hacia Dios, que mi corazón reclama alimento, que necesito sentir mucho, deshacerme, abrasarme. El amor me ahogaba. Wagner me había despertado”. (La Quimera: 1905).
} 
1. Música religiosa y música de Wagner en íntima vinculación, y aquí su "Es posible que según la teoría de Wagner, mi oído necesite, para penetrarse de la belleza de la música, el auxilio de mi vista (...). En el templo todo os sugiere el misterioso estado de ánimo a que la música responde fielmente (...) la semiobscuridad, el olor casi disipado del incienso, el parpadeo de los cirios en el altar del coro (...), constituyen una decoración del gusto de Wagner (el artista que mejor ha comprendido la estrecha, íntima relación de la mise en scène teatral y la mise en scène religiosa) (...) en la iglesia la sensación de realidad contribuye a realzar la poesía". (LIA, 8/X/1906).

2. La ubicación del Santo Grial, su significado: España, el Santo Grial, MontserratMonsalvat, Valencia, Cebreiro (Lugo) y Parsifal, su españolidad (la vimos también con el Lohengrin) como leyenda y mito griálico.

el castillo de Monsalvato, donde se alza el templo del santo Grial. Y juraría que era en España (...) [el Grial] Era el talismán por excelencia, pero lo era sólo para los puros, los que estuviesen en gracia y fuesen caballeros en todos sus actos y en el ilustre origen de su estirpe. Porque el Grial es aristocrático, y sus templistas no se reclutan sino entre los hazañosos y bien nacidos. Ni mancha ni villanía, ni mancha tampoco de pecado (...) su conquista está reservada a Perceval o Parsifal, de conciencia clara como el diamante.

(...) Y Monsalvato...idónde se encuentra? Monsalvato no es sino Monserrate [Havelock Ellis, hispanista] (...) dice Teodoro Llorente en su obra Valencia: "Allá por los siglos XIII y XIV, había en el monasterio celebérrimo de San Juan de la Peña un precioso cáliz (...)", porque qué hermoso sería poseer el Grial y Monsalvato, el Cáliz de la Cena y la montaña "en tierra desconocida. (LIA, 20/XII/1909).

Montserrat no es sino Monsalvato [ideas de H. Ellis], y los terribles riscos que guarnecen la montaña por la parte donde sus breñas se rajaron en el momento de la crucifixión, son Ilamados "los custodios del Grial". En esas rocas de tan extraña hechura están, pues, encantados, Tituriol, el que sólo revivía por la contemplación del Grial; Amfortas, el herido de la lanza, la víctima de Kligsor; Parsifal, el sencillo, el piadoso, el compasivo, el que por la misericordia pudo restaurar el reinado del Grial; Lohengrin, su hijo, el esposo momentáneo de Elsa de Brabante; y todos los templistas, guardadores del encanto y el arcano, que esperan el descenso de la paloma simbólica, del Espíritu, y que no lo supieron aguardar todos, ya que algunos se dejaron engañar y engatusar por la maga Kundry...(...) No muy lejos de Montserrat, en Valencia, se conserve en la catedral un cáliz que ha pasado por ser el de la Cena, y bien pudiera ser la mágica copa del Grial...Este cáliz procedía del monasterio de San Juan de la Peña (...) El juicio que hace Hevelock Ellis del carácter español, desde la montaña de Montserrat o Monsalvato, revela la impresión que el espectáculo le ha producido (LN, 17/I/1910).

[más sobre la españolidad de Parsifal, el Cebreiro lucense, La España árabe...] La parte que corresponde a España en Parsifal no es pequeña. Unánimemente, y sin negarlo el propio Wagner, Monsalvato y el Jardín encantado de Klingsor se sitúan en territorio español; y según tradición muy difundida, el propio cáliz del Grial se custodia en la catedral de Valencia; sin hablar del otro cáliz del "Santo Milagro" que muchos creen el Grial verdadero, y que se halla en las áperas montañas del 
Cebrero, en Galicia (...) Lo indudable es que Wagner, al pensar en situar su Parsifal aun dentro del terreno vago de la leyenda, pensó en España, la España árabe, para los palacios y jardines encantados del brujo, y en la España gótica, para los dominios del Grial. (LN, 10/II/1914).

2. 1. El cáliz (físico) de Valencia:

Yo tuve la ocasión de ver la primera de estas copas "descendidas del cielo", y aún de describirlas, no recuerdo dónde (...) Si el cáliz de Valencia fuese el Santo Grial, sería también el Cáliz de la Cena, y puede serlo, a juzgar por la época que representa, y que Chabas ["docto canónigo de la catedral"] no consideraba anterior al siglo VI. La reliquia es de estilo visigótico, de ágata la copa, de oro o plata sobredorada (...) Lo incrustan pedrerías (LN, 10/II/1914).

2. 2. Vinculación de los caballeros del Santo Grial de Monsalvat con la Orden de los Templarios:

Cualesquiera que sean las vicisitudes de la leyenda del Grial, para mí su fondo de realidad histórica está en la orden de los templarios, que si no lo custodiaban el Grial, custodiaban como Amfortas el culto del Espíritu (LN, 17/I/1910).

3. El estreno de Parsifal en Madrid (Enero 1914) y la defensa y madurez del "nuevo" público del Teatro Real: "Wagner ha conquistado muy poco a poco a los madrileños; tan poco a poco que hará ya más de cuarenta años que aquí se oyó la primera ópera del mago de Bayreuth" (LIA, 19/I/1914, todas las citas de este punto se extraen de aquí, uno de los más referenciados artículos parsifalianos). Algunas referencias más al respecto del comportamiento madrileño el día del estreno ya las hemos expuesto en texto y notas, casi todas extraídas del artículo de La llustración Artística (LIA).

Se reitera la idea del estreno desde La Nación bonaerense (LN, 10/II/1914):

Parsifal se esperaba en Madrid, como en todas partes (...) La prohibición estimularía el apetito, y cuando Parsifal pudiese ser cantado en todas partes, revestiría su aparición la mayor transcendencia. El asunto de Parsifal, que muchos suponen obra maestra de Wagner, no está tomado, como generalmente se cree, de la tradición alemana, sino de la leyenda céltica del "Grial", del ciclo carolingio...

En definitiva, en LIA, 21/XII/1914 ya se llega a afirmar: "Hoy, el público madrileño empieza a ser uno de los más adictos a Wagner" y "la actitud del público de Madrid en esta ocasión demuestra hasta qué punto Wagner ha consolidado su dominio. Aunque en los palcos se guarda silencio, y silencio profundo" (LN, 10/II/1914). 
3.1. Parsifal respecto al conjunto total de la obra wagneriana, especialmente con Lohengrin, pero pendiente una "temporada wagneriana", "empezando con El Barco fantasma y acabando en Parsifal". Se apunta el inédito hecho de haber retenido durante treinta años los derechos sobre la obra de Parsifal en Bayreuth y sólo haberse podido representar desde 1914 (LN, 10/II/1914).

4. Estreno del Parsifal. Incidentes, "la representación dura demasiado":

Y yo, que soy apasionada de Wagner, me apresuro a reconocer que, en efecto, dura demasiado esta su obra maestra y maravillosa. El sentido de la proporcionalidad es una cualidad latina, que le faltaba al gran germano. Tengo el valor de mis convicciones, y como pienso, lo digo. Si Wagner hubiese practicado este precepto de estética general, nadie dejaría de inclinarse extático ante él. En Parsifal hay dúos o diálogos que son excesivamente prolijos, y dirían lo mismo si fuesen cortos. Casi toda la parte de Gurnemanz adolece de este defecto de prolijidad y lentitud (...) La lentitud de los diálogos: El de Kundry con Klíngsor; el mismo de Kundry con Parsifal (lo repito tímidamente) pudieran ser más breves (...) Lo mismo pienso de las primeras escenas del acto tercero (...) Los propios actores no saben qué hacer (...) Dirán que todo esto es falta de respeto a Wagner. Nadie más entusiasta del maestro que yo. (LIA, 19/I/1914).

...creo que me da derecho a votar con los que encuentran que Parsifal es magnífico..., pero largo. Sí: el espíritu germánico, más penetrado de la grandiosidad que de la proporción, se explaya, se detiene, contando con la atención sostenida e infatigable de un pueblo más flemático que nervioso. La poderosa calma alemana se revela también en este sumo artista, gloria de la raza y asombro de la humanidad (LIA, 21/XII/1914).

[y una concesión para el "sufrido" público madrileño...] Las horas son seis. Por admiradora que yo sea de Wagner, y lo soy hasta la médula, y lo he probado con la pluma infinitas veces, encuentro que sobran dos (...) Y así como en una ocasión yo tomé el partido de Wagner contra el público (...) diré que pudiera el público tener el derecho de adormecerse un poco en algunos trozos de Parsifal; pero no lo hace, porque le despabila la seguridad de sentirse transportado a las más altas cimas de la emoción estética y religiosa (...) en tantos magníficos momentos de inspiración que hacen de esta obra la esencia de la belleza en la música, y del misticismo en el sentimiento, se expresa la sublimidad de la redención por la sangre (LN, 10/ II/1914).

\section{El poema y la partitura en Parsifal:}

Como siempre sucede en la obra de Wagner, el libreto está a la altura de la música. Para escribir estos libretos admirables, Wagner no ha empleado más que un procedimiento: no inventar; limitarse a aprovechar la tradición y la leyenda, desentrañando, con la poesía y la música, su oculto simbolismo. Para Wagner, como para Baudelaire, el mundo es una selva de símbolos, y voces misteriosas los murmuran, saliendo de los árboles centenarios de esa selva.

6. Parsifal y el credo cristiano, entre el debate y la interpretación: 
En Parsifal, hizo Wagner algo más sencillo: tomó como fuente de inspiración los dogmas de la Iglesia Católica: la Redención por la sangre, la Eucaristía. Parsifal es una misa; no cabe idea humana más genial (...) Por cierto, que en la mezquindad de criterio que tanto ha cundido (...) no faltó quien se escandalizase porque, en Parsifal, consagran la sangre divina, y desde la cúpula un coro admirable entona este cántico: ¡Tomad mi cuerpo, tomad mi sangre, para que nunca os olvidéis de mí! (...). En Parsifal late lo más elevado y hermoso del catolicismo. El profundo sentido del inefable sacrificio no ha sido, si acaso vuelva a ser, expresado con tan mágica sugestión. La emoción estética de Parsifal es, al mismo tiempo, una emoción completamente religiosa.

¿Qué es Parsifal? Una misa, un holocausto. Es el triunfo del dogma del amor sobre el infierno, sobre el pecado, sobre las pasiones (...) Wagner ha presentado contra la redención por la sangre divina contenida en el Grial, los ardides del mago Klingsor. Porque en efecto, la mayor parte de las viejas religiones impuras no eran más que ritos mágicos (...) Klíngsor, el moro, es tan simbólico como Parsifal, el fervoroso, "el puro" por antonomasia. Y sobre este tema escribió Wagner la música más estremecedora de belleza: esa página que transporta a todos los públicos y que se llama la Consagración del Grial.

Se creería que este sello católico (...) fuese incompatible con el espíritu protestante. $\mathrm{Y}$ acaso lo sea, y quizás por eso haya sufrido la contradicción y negación del maestro (...) el culto a Wagner es cosa alemana, pues en Francia Ilegaron al extremo de silbarle (LIA, 21/XII/1914).

[se afirma Parsifal (con Tannhäuser) no como obra exótica, sino tradicional y católica: comparación con San Juan de la Cruz, Van Dyck y el beato Angélico] La misa y la confesión, y no otra cosa, forman el asunto de estos dos grandes dramas musicales, aplaudido el segundo repetidamente en Madrid (...) Es, en efecto, Parsifal el drama eucarístico, y la apoteosis musical del catolicismo. Nunca el amoroso misterio del cuerpo y la sangre inflamó la mente de ningún artista con más férvido y ardiente transporte creador (...) No debe extrañarnos que el ilustrado catalán Domenech, al consagrar a Parsifal detenido estudio, declare que esta obra la escribió Wagner nada menos que bajo la inspiración del Espíritu Santo y que Parsifal constituye, más allá del arte, un milagro auténtico, de suerte que Wagner, intérprete esta vez de la voluntad celestial, no llegó a saber nunca lo que Parsifal significa: no pudo reconocer la transcendencia de su propia obra. Tal opinión sobre la inconsciencia de Wagner al crear el más sublime de sus dramas musicales (...) Parsifal vino providencialmente a destruir la afirmación de Hartmann, que da por muerta a la religión, puesto que ya no inspira obras de arte (...) la considero una demostración de que el fondo de la belleza musical ha sido siempre religioso. No es sólo en Parsifal (...), donde las mejores páginas de Wagner transcienden a música de iglesia y a música de ángeles; esa vena profunda corre también en Lohengrin, en Tannhäuser, en Tristán e Isolda, y en muchas páginas de la colosal tetralogía (...) Wagner dejó escrito que toda obra de arte es "religión presentada en forma viviente", y su objeto más alto, "revelar las sagradas arcanidades del hombre interior, donde la verdadera religión tiene su base. (LN, 17/I/1910).

\section{Parsifal (al lado de "sus nobles hermanas" wagnerianas) como "obra redentora"} frente al mal gusto y la mediocridad del arte:

$¡$ ¡Ah, si Parsifal y sus nobles hermanas, las otras bellas creaciones de Wagner, pudiesen redimirnos del "Tápame, tápame...", y de la creciente manía taurómaca; 
o al menos redujesen estas plagas a sus justos límites, y al puesto secundario que debieran ocupar en la vida nacional! ¡Si la vacuna alemana contra la viruela de la grosería y ferocidad nos librase del contagio!.

Me Ilama poderosamente la atención que Pardo Bazán dejara "escapar" sin más la figura y personaje femenino de Kundry (la menciona como maga y encantadora de caballeros -1910- y se refiere varias veces a sus largos diálogos con Klíngsor y el mismo Parsifal, 1914), o incluso la referencia de Parsifal por su madre Herzeleide, padre aquél de Lohengrin, su hijo.

La interpretación más canónica del Parsifal sobre la figura femenina de Kundry, apunta inicialmente hacia la naturaleza pecadora de la mujer (Eva bíblica), su lucha personal entre su búsqueda y experiencia con el Salvador, y su "vocación" / inclinación hacia el mal (su risa, su "lote del pecado"). Su culpa fue sin duda la profanación del cáliz redentor, pero su anhelo y combate la enfocan en su posible (aunque difícil) salvación. El símbolo del conflicto mental de Kundry es la herida asestada a Amfortas, el varón caído por la impureza, y éste, claro está, también ansía la salvación. Bajo el poder de Klíngsor, la hechicera manifiesta su esclavitud para con el pecado, seduce contra su más íntima voluntad luminosa, pero ejecuta. Como en un par opuesto en forma de yin/yan, bajo el poder del mal, aún le queda fuerza espiritual para ser mensajera del Grial, también contra su voluntad perversa, pero es capaz de estar pisando tierra sagrada: su posible liberación llegará por su sometimiento y mortificación en el servicio (casi esclavitud, trabajo duro) a las gentes del Grial. Todo en ella es tristeza, combate arduo interior y exterior ("el que te desafíe te liberará"), desesperación, clamor de piedad. Kundry se redime mediante la lanza conquistada por Parsifal, un nuevo bautismo que el reciente rey del Grial le ofrece por medio de las lágrimas (el símil novotestamentario de Jesucristo siéndole lavados los pies por una pecadora) en medio de praderas florecidas del Viernes Santo. La vida, apuros y símbolo de la mujer luchadora por la perfección, contra "sí misma", la guerrera interior y exterior que procura sin límites su purificación: un personaje femenino tremendamente atractivo para un lector, oyente e indagador intelectual.

El hombre Parsifal, se unifica con el recuerdo y alma de su madre Herzeleide, mediante el símbolo del Bien, el cisne a quien mata "inocentemente" (el pecado humano está en el mal en sí mismo, no desde la "voluntad explícita" del hombre): la naturaleza sufre y Ilora por la desviación de Parsifal, pero la salvación/redención de todo comienza a tomar forma desde que aparece el recuerdo de la figura de la Mujer Eterna: su madre Herzeleide, vencedora ya del pecado, mediante el Amor. Ambos aspectos del símbolo femenino, entre las tinieblas y la luz redentora, no pudieron pasar de puntillas y sin más por los gemelos del paraíso del Real o en sus lecturas por el último de los dramas wagnerianos. No contenta con la mujer y personaje 
de Elsa de Brabante, esta figura de Kundry debía ser para ella de un simbolismo y profundidad más que sugerente...

Pasado ya el cambio estético y el espiritualismo converso de Silvio Lago en La Quimera (1905), la consolidación de un nuevo código aristocratista (M. Aguinaga, 1993), incluso el impresionismo pictórico de sus relatos, el dominio de técnicas narrativas cada vez más refinadas en Dulce Dueño (1911), a la Condesa de Bazán en la segunda década del nuevo siglo XX, el modernismo wagneriano le venía como anillo al dedo, aunque en la altura de 1914, ya iba publicando una biografía de Hernán Cortés y sus hazañas, se había introducido en los fogones de Francia y la España profunda, y se preparaba para las agonías de un comienzo y final de una guerra desgarradora para toda Europa y mundo, como fue la Gran Guerra mundial (Porvenir de la literatura después de la guerra, 1917), dando paso a una escritora navegando entre aguas de la sensible admiración por su Francia aperturista, y la belleza y estética germana. Saldrá siempre bien parada de éste y otros conflictos. Pero Parsifal lo redime todo.

\section{CONCLUSIONES.}

La contemporaneidad de nuestra prometedora novelista coruñesa con la vida y obra de Richard Wagner es importante, aunque no se conocieran en persona. Cuando la Señora de Quiroga reflexiona de su primer impacto en Viena (1873), hacía poco que se había colocado la primera piedra del Nuevo Teatro de Bayreuth, se iba terminando la partitura del Ocaso de los dioses (Götterdämmerung) y los esplendores crepusculares del Parsifal, innato pero ya esbozado en su texto. Vive pues Doña Emilia una juventud de los años 1860, coetánea hasta el fallecimiento del compositor en 1883: una simultaneidad vital entre los dos genios.

Lo que la sensibilidad y experiencia wagneriana (música, texto y visualización del drama) fue dejando e interiorizando en lo íntimo y anímico de la conciencia de la persona de Emilia Pardo Bazán, nunca lo sabremos. Al oír, ver, leer, vislumbrar, intuir, discernir, comparar, diseccionar, analizar, sentir los Dramas musicales, nuestro personaje y persona lo intenta guardar con siete llaves, y ese es realmente el tesoro dado desde el legado de la obra de Richard Wagner. Menor es sin duda lo que pudo exteriorizarse desde la intelectualidad de la autora, dado el aprendizaje en lo operístico y wagneriano, esto es, principalmente artículos periodísticos en forma de relatos de viajes o crónicas de opinión, y secundariamente, en los matices y referencias que observamos de dicha materia en sus novelas y relatos cortos de su amplia producción literaria. A ello nos debemos de atener. 
La escritora Emilia Pardo Bazán, en un momento de su vida es atraída por el mundo artístico, estético y social que es y conlleva la Ópera. No se siente inicialmente muy melómana y menos aún una entendida o experta en el tema, pero su atrevimiento intelectual le lleva a introducirse en el mundo de la música: obras, autores, personajes, voces, lenguaje, público, teatros líricos, cantantes, orquestas, instrumentos, escenografías, partituras.... Al final de una etapa, y como demostramos en la elección del léxico y ambientes que coteja en su obra general, se hace toda una buena aficionada del mundo y cultura musical; con el paso del tiempo estará mejor capacitada para versar sobre el mundo musical (su crónica sobre el estreno del Parsifal en Madrid es de una crítica musical excelente), aunque ella de vez en cuando acuda a una útil humildad (¿captatio benevolentiae?), muy literaria por otra parte.

Liberada también por el mundo artístico, paisajístico, legendario, urbano, musical, literario de lo alemán y centroeuropeo, y hasta de personajes como el Káiser Guillermo II o la emperatriz Sissí, a Doña Emilia no le quedará otro remedio que alinearse en el bando pro-aliado francés en la dura contienda mundial de 19141918, sobreviviendo siempre su sincera admiración por todo lo germánico, y ya en especial por Wagner.

Richard Wagner significa para la joven y madura escritora coruñesa, una apuesta por la regeneración de la sociedad a través de este Arte y su mensaje, un Arte del Porvenir, un Drama de la futura estética, posmodernista y del siglo XX. La música, desde el despertar de la obra wagneriana, ya no será, para siempre, la misma. La apuesta por el contenido, forma y lenguaje del wagnerismo es rápidamente captado (Buque Fantasma, en Viena, 1873) por la autora, en momentos iniciales en los cuales no era tan fácil adherirse a la nueva estética musical y un "Drama musical", un paso más allá de la Ópera, una profundización en lo literario (advertida de la importancia del texto de los libretos operísticos y de la profundidad a que la cronista los somete desde la mismísima historia de la literatura, legendaria o medieval) y escenográfico, siendo de las primeras plumas en denunciar la falta de gusto y delicadeza en las versiones de determinados directores de escena...: toda una advertencia hasta nuestra actualidad, pues el compositor alemán es todo eso y algo más.

La que será Condesa de Bazán descubre la obra wagneriana en Viena, admirará ya sin reservas, la definitiva nueva forma musical-literaria en los Lohengrin del Teatro Real (desde1881) y La Walkyria (1899), para así prepararse a la pasión más elevada posible en los "éxtasis" de las Consagraciones del Parsifal (1914).

Los cuadros con las referencias a todas las óperas y dramas wagnerianos deberían servir de reflexión sobre la importancia del mundo de la ópera, forma, mensaje y estética, en especial el de R. Wagner, en la obra global literaria de la inquieta y relevante en múltiples facetas intelectuales, que fue y es Doña Emilia Pardo Bazán. 


\section{E.PARDO BAZÁN, ÓPERA GENERAL Y R. WAGNER BIBLIOGRAFÍA GENERAL}

Alier, Roger (1986): El Gran Teatro del Liceo, ed. Daimon, México D. F.

Andrade Malde, J. (1998): La Banda municipal de La Coruña y la vida musical de la ciudad, ed. Ayto.-Concello da Coruña, Coruña.

Armesto, V. (1973): Verbas galegas, ed. Galaxia, Vigo.

Barreiro, C. (2008): "La prensa española ante la Primera Guerra Mundial", Rev. Arbil 118. También: http://www.arbil.org/arbil127.htm

Barreiro Fernández, J. R. (1986), Historia de la ciudad de La Coruña, ed. Voz de Galicia, Coruña.

Bravo, I., Graells, G.- J. (1983): Espais wagnerians, ed. Institut del Teatre, Diputació de Barcelona, Barcelona.

Caso, A. (1999): Elisabeth, emperatriz de Austria-Hungría. La verdadera historia de Sissí, Planeta, Barcelona.

Colino, A. y Grandío, E. (1994): La Coruña en el siglo XIX, Via Láctea, Oleiros (A Coruña).

Delaisi, F. (1912): La fuerza alemana, ed. Celestino Peón, Pontevedra.

Encabo Fernández, E. (2009): “¿Wagnerismo à outrance?: Emilia Pardo Bazán amte "La Música del Porvenir" in La Literatura de Emilia pardo Bazán (edits. J. M. Glez. Herrán, C. Patiño y E. Penas), Caixa Galicia, Coruña, pp. 263-272.

González Herrán, J. M. (1998): "Veinte años de música en España (18961914) a través de los artículos periodísticos de Emilia Pardo Bazán" in Galicia en América: música. Cultura e sociedade arredor do 98, Universidade USC, Santiago de Compostela, pp.39-56. También (2006) Biblioteca Virtual Universal (www. biblioteca,org.ar).

Gosset, Ph., Ashbrook, W., Budden, J. (1988): Maestros de la Ópera italiana-1. Rossini, Donizetti, ed. Muchnik, Capellades (Barcelona).

Hamilton, M. (1996): The wordsworth. A-Z of Opera, Wordsworth Reference, Hertforshire (UK.).

Infiesta, M., Mota, J. (1992), Mestres Cabanes, Labor, Barcelona.

Iglesias De Souza, L. (1981-1882-1883): "Algunas referencias a la ópera en La Coruña en el siglo XIX", Rev. Abrente, n 13-14-15, pp. 73-110.

Lippmann, A., Porter y Carner, M. (1988): Maestros de la Ópera italiana-2. Bellini, Verdi, Puccini, Muchnik, Capellades (Barcelona).

Magee, Bryan (2013): Aspectos de Wagner, Acantilado, Barcelona.

Marsillach, Joaquim (1985): Richard Wagner, L'Holandès Errant, Barcelona.

Mota J., Infiesta, M. (año s/n; 1980 aprox.): Escritos wagnerianos, edic. propios autores. 
Ortiz de Urbina y Sobrina, Paula (2007): Richard Wagner en España: la Asociación Wagneriana de Madrid (1911-1915), Univ. Alcalá, Alcalá de Henares (Madrid).

Patiño, Cristina (1992-1993): "Emilia Pardo Bazán y la música", Revista Inst. José Cornide $n^{\circ}$ 27-28, año XXVII-XXVIII, A Coruña.

Paz Canalejo, Juan (2006): La Caja de las magias. Las escenografías históricas en el Teatro Real, Univ. Castilla-La mancha, Ayto. Madrid, Madrid.

Rey Majado, Áurea (2000): A Coruña y su música. El primer orfeón coruñés (1878-1882), Concello da Coruña, Coruña.

Ríos Camacho, X. C. (2001): "Asimilar la heroicidad del Siegfried", Rev. Crónicas Wagnerianas $\mathrm{n}^{\circ}$ 4, pp. 12-16.

Idem (1993): "Els Mestres Cantaires", Rev. Fulls Wagnerians nº 6, pp. 3-5, 1983.

Idem (2012): "En defensa de El Último de los Tribunos, de vuelta con el Rienzi en el Teatro Real de Madrid (1876-2012)", Rev. Crónicas Wagnerianas n 5, pp. 12-18, 2012.

Idem (2011): "Isolda y Tristán sobre fondo azul marino", Rev. Crónicas Wagnerianas $\mathrm{n}^{\circ} 4$, pp. 19-21.

Idem (2011): "O busto de Richard Wagner no Teatro Rosalía de Castro da Coruña (1870-1872)", Rev. Crónicas Wagnerianas nº 6, 2013, pp. 10-13.

Idem (1983): "Tannhäuser: mi primera obra", Rev. Nothung no 26, pp. 10-11.

Idem (2013): "Tristán en Kareol...o la suprema alegría de volver a la tierra positiva. Crónica histórica de Tristán e Isolda en el $61^{\circ}$ Festival de Ópera da Coruña (28/IX/2013), año del bicentenario de R. Wagner / Tristan in Kareol... or the supreme happiness of returning to the positive earth. Historical chronicle of Tristan and Isolde in the $61^{\circ}$ Festival Opera of Corunna (28/IX/2013), R. Wagner's Bicentennial year", Rev. Crónicas Wagnerianas n 7-8, pp. 35-58.

Idem (2011): "Una noche y Götterdämmerung para recordar en el 30 aniversario de nuestra coruñesa Asociación Wagneriana (1980-2010)", Rev. Crónicas Wagnerianas $\mathrm{n}^{\circ}$ 2, pp. 1-8.

Sánchez García, J. A. (1995): El Teatro Rosalía de Castro, ed. Via Láctea, Oleiros (A Coruña).

Idem (1995): "La construcción de la ciudad burguesa en Galicia: A Coruña (1840-1868)", Rev. Abrente, A Coruña.

Idem (1997): La Arquitectura teatral en Galicia, Fund. Barrié de la Maza, Coruña.

Soraluce Blond, J. R. (1988), "El espacio del espectáculo: los primeros teatros de Galicia", in Boletín Académico ETSAC, pp. 26-37.

Sotelo Vázquez, Marisa (2007): "Emilia Pardo Bazán y el Folklore gallego", Garoza, Revista de la Sociedad Española de Estudios Literarios de Cultura Popular, no 7, pp. 293-314. 
Steward Chamberlain, H. (1980): El drama wagneriano, Nuevo Arte Thor, Barcelona.

VV. AA. (Comis. F. J. López Ríos) (2003): Cincuenta años de Ópera en La Coruña: Amigos de la Ópera, Deput. da Coruña, Concello da Coruña, Coruña.

VV. AA. (Dir. J. Mota) (1978): Wagneriana, vol. II, Bau, Barcelona.

VV. AA. (Comis. J. A. Sánchez García) (1995): La escena de la ciudad. El Teatro Rosalía de Castro, Ayto. Coruña.

VV. AA (Coord. Javier Vizoso) (2001): Verdi y el XIX. 49 Festival de Ópera de La Coruña, 2001, Consorcio para la Promoción de la música, Coruña.

VV. AA (2009): "Colaboradores de Renovación Española" in: http://www. filosofia.org/hem/med/m037.htm

Vedía y Gossens (1975): Historia y descripción de la ciudad de La Coruña, Inst. Estud. Coruñeses José Cornide, Coruña.

Wagner, Richard (trad. y comentarios Á. F. Mayo) (1982): Los Maestros Cantores, ed. Daimon, Manuel Tamayo, Barcelona.

Ídem (1975), Escritos y confesiones, Labor, Barcelona.

Idem (1952), La poesía y la música en el drama del futuro, Espasa Calpe, Buenos Aires.

Idem (1977), Mi Vida, Nuevo Arte Thor, Barcelona.

\section{OBRA DE/SOBRE EMILIA PARDO BAZÁN}

Acosta, Eva (2007): Emilia Pardo Bazán. La luz en la batalla, Lumen, Barcelona.

Aguinaga Alfonso, M. (1993): "La Quimera", orientación hacia el misticismo, Do Castro, Sada (A Coruña).

Faus, P. (2003): Emilia Pardo Bazán. Su época, su vida, su obra, Fundación Barrié, Coruña.

Ferreiro Alemparte, J. (1971): "Vinculación literaria de dos escritores gallegos en castellano: D. Emilia Pardo Bazán y D. Ramón del Valle-Inclán", in Rev. Grial n³4.

Franz, Thomas R., "La Madre Naturaleza" y "Paz en la Guerra": el intertexto perdido", Cuadernos de la Cátedra Miguel de Unamuno, n³ 34, 1999, pp. 29-40. Universidad de Salamanca.

Freire López, A. Mª (2003), "La obra periodística de Emilia Pardo Bazán", Estudios sobre la obra de Emilia Pardo Bazán: actas de las jornadas conmemorativas de los 150 años de su nacimiento, Fundación Pedro Barrié de la Maza, Coruña, pp. 115-132.

Jiménez Morales. Ma I. (2008): "Emilia Pardo Bazán, cronista de París (1889)", Revista de Literatura, julio-diciembre, vol LXX, no 140, pp- 507-532.

Pardo Bazán, Emilia (1989): Dulce dueño, Castalia, Madrid. 
Idem (1917): Porvenir de la literatura después de la Guerra. Lectura dada en la Residencia de Estudiantes la tarde del 5 de diciembre de 1916, Residencia de Estudiantes, Madrid.

Idem (1999): Obras completas, I. Pascual López, Un viaje de novios, La tribuna, El cisne de Vilamorta, Fundación J.A. de Castro.

Idem (1982), La sirena negra, La Gaya Ciencia, Barcelona.

Idem (edic. Carlos Dorado) (2005): La vida contemporánea, Ayuntamiento Madrid-Hemeroteca Municipal, Madrid.

Idem (edic. Ignacio J. López) (¿?): La madre Naturaleza, Cátedra, Madrid.

Idem (edic. Marina Mayoral) (1991): La Quimera, Cátedra, Madrid.

Idem (edic. Juliana Sinoras Maté) (1999): Emilia Pardo Bazán. La obra periodística completa en "La Nación" de Buenos Aires (1879-1921), 2 vols., Deput. Prov. da Coruña, Coruña.

Idem (edic. Marisa Sotelo Vázquez) (2006): Un poco de crítica. Artículos en el ABC de Madrid (1918-1921), Universidad de Alicante, Alicante.

Idem (edic. Tonina Paba) (2006): Viajes por Europa, Bercimuel, Madrid.

Idem (edic. Tonina Paba) (2006): Viajes por España, Bercimuel, Madrid.

Ídem (edic. B. Varela Jácome) (2009): La Tribuna, Cátedra, Madrid.

Idem (2013): "Miquiño mío", Turner, Barcelona.

VV. AA. (Coord. X. Santiso) (2008): Catálogo da Casa- Museo Emilia Pardo Bazán, RAG e Cas-Museo EPB, Dep. Prov. da Coruña, A Coruña.

Villanueva, Darío (2003): "El cosmopolitismo literario de Emilia Pardo Bazán", in Estudios sobre la obra de Emilia Pardo Bazán (Coord. Ana M ${ }^{a}$ Freire), Fund. P. Barrié de la Maza, Coruña, 2003, pp. 63-80.

URL POR TEMAS

http://www.arbil.org/(78)cris.htm (aliadófilos y germanófilos)

http://www.rtve.es/alacarta/audios/escritores-en-el-archivo-de-rtve/emiliapardo-bazan-wagner-parsifal/1091936/ (EPB, Wagner y Parsifal, con audio)

http://campus.usal.es/ revistas trabajo/index.php/0210-749X/article/ viewFile/1736/1795 ("La madre Naturaleza y Paz en la guerra: el intertexto perdido", Thomas R. Franz)

http://books.google.es 